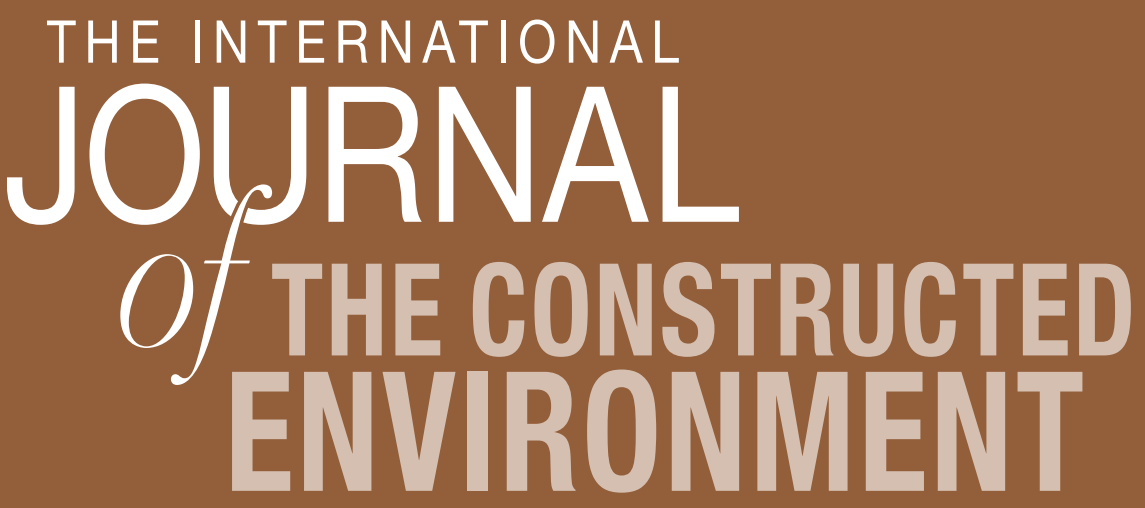

Volume 1, Issue 4

Lines of Sight, Paths of Socialization: An Axial Line Analysis of Five Domestic Designs by Richard Neutra

Michael Dawes and Michael J. Ostwald 
THE INTERNATIONAL JOURNAL OF THE CONSTRUCTED ENVIRONMENT

http://constructedenvironment.com/Journal/

First published in 2012 in Champaign, Illinois, USA

by Common Ground Publishing LLC

www.CommonGroundPublishing.com

ISSN: $2152-7857$

(C) 2012 (individual papers), the author(s)

(c) 2012 (selection and editorial matter) Common Ground

All rights reserved. Apart from fair dealing for the purposes of study, research, criticism or review as permitted under the applicable copyright legislation, no part of this work may be reproduced by any process without written permission from the publisher. For permissions and other inquiries, please contact

<cg-support@commongroundpublishing.com>.

THE INTERNATIONAL JOURNAL OF THE CONSTRUCTED ENVIRONMENT is peerreviewed, supported by rigorous processes of criterion-referenced article ranking and qualitative commentary, ensuring that only intellectual work of the greatest substance and highest significance is published.

Typeset in Common Ground Markup Language using CGPublisher multichannel typesetting system

http://www.commongroundpublishing.com/software/ 


\title{
Lines of Sight, Paths of Socialization: An Axial Line Analysis of Five Domestic Designs by Richard Neutra
}

\author{
Michael Dawes, The University of Newcastle, NSW, Australia \\ Michael J. Ostwald, The University of Newcastle, NSW, Australia
}

\begin{abstract}
Richard Neutra, a pioneer of modern architecture, produced a famous series of house designs in California throughout the 1940s and 1950s. In this paper five of these houses are investigated to test three related facets of Neutra's design theory; the social function of the exterior and the use of long, controlled sight-lines to shape the way space is observed and comprehended. The houses are investigated using Axial Line analysis; an established method that models the way spaces are experienced and understood through movement. The method identifies-through visual analysis and the application of graph theory mathematics-several properties of each design including visual depth, permeability and intelligibility; properties which broadly correspond to the three facets of Neutra's theory. Through this compound process, the paper not only tests the application of these parts of Neutra's design theory but it also develops a new reading of the relationship between form and topology in these houses.
\end{abstract}

Keywords: Space Syntax, Axial Line Analysis, Richard Neutra

\section{Introduction}

$\mathrm{W}$

HILE CONVENTIONALLY CELEBRATED as the archetypal Modernist architect, Richard Neutra's designs were only superficially indebted to the tenets of European Functionalism and the values of the International Style. Instead, Neutra's designs were profoundly influenced by theories connecting bodily reactions to spatio-phenomenological stimulus. These theories led Neutra to design buildings in such a way as to choreograph the emotional response of visitors through visual excitation; a process that, in practice, relied on carefully controlling the way people see, move through and comprehend space. Three, interrelated facets of Neutra's design theory are the focus of the present paper: the high level of reliance on exterior circulation; the use of long sightlines to draw the body through space; and the need to produce spaces which are readily understood. To date, none of these have been analysed using mathematical means to test their actual significance in Neutra's architecture.

The present paper uses a variation of the Axial Line method-an approach developed as part of the Space Syntax suite of analytical tools-to undertake the first mathematical investigation of the impact of three facets of Neutra's design theory on his domestic architecture. Focussing on five Californian houses built between 1946 and 1958, this research analyses each house to identify the relative depth of the plan, including the "shortest path from the formal entrance (most public space) to the main bedroom (most private space) of each dwelling" [Hanson 1998, 243]. Thereafter the plans are analysed to determine the extent to which exterior connections control the social function of the house. The integration values

The International Journal of the Constructed Environment

Volume 1, Issue 4, 2012, http://constructedenvironment.com/Journal/, ISSN 2152-7857 
of the plan are then determined, classified and grouped in order to reveal the way in which vistas in the plan dominate and control the design. These integration and connection values are combined to measure the relative intelligibility of each plan; a process that determines the degree to which paths and vistas in the house can allow a visitor to experience the complete design. Though this research the paper not only tests three specific facets of Neutra's design theory, it also offers an alternative way of viewing his domestic architecture and, in doing so, demonstrates a rare application of the Axial Line method to domestic design analysis.

\section{Neutra and Biorealism}

Austrian born, American Architect, Richard Neutra produced designs which are typically interpreted as canonical Modernist works; using new technology and industrial materials to express the functional properties of a building and the spirit of the era [Boesiger 1996; Hines 1982; Sack 1992]. However, while Neutra's designs may appear similar to those of other pioneering Modernist architects, the theory underlying his designs is completely different [Lamprecht 2000; Lavin 2004].

Neutra's design values were shaped by both his training at Vienna's Technische Hochschule and by the Viennese architectural culture of the day; a culture dominated by Adolph Loos and Otto Wagner. However, it is less well known that Neutra identified the Experimental Psychologist Wilhelm Max Wundt as having the greatest impact, of any single person, on his architectural ideas [Marlin 1989; Lamprecht 2000]. In the late $19^{\text {th }}$ century Wundt employed experimentation and observation to uncover the relationship between human perceptions and reactions. Lavin [2004] descibes this as a process wherein the act of sensing "a physical object in the world" triggers a transference "of perception until it [becomes] first a sensation registered in the brain and then a feeling" [35].

The design philosophy developed by Neutra, from his studies of Wundt's theories, was named Biorealism. Fundamentally, Neutra's theory called for design to (a) support a reconnection with nature, (b) to limit the impact of chaotic environments and (c) to address the primary sensory needs of the human body. For Neutra [1956], human response is a "consequence of shape, of the shapes which surround us" [20]. While Neutra believed that all of the senses were required to achieve the most effective response, he supports Wundt's assertion that sight is the most primitive and powerful sense. Thus, Neutra [1956] argues, that a person's "greatest awareness [...] is linked to our visual impression of the house which we 'see not merely to see' but see in order to act upon vision" [13]. Therefore, he suggests that vision activates "a person's locomotor urges" [14], causing them to follow a certain path or look in certain directions. Consequently, a well-formed design can create vistas, paths and points of interest that "can alarm the eye" [14] and attract the body.

Neutra employed several design strategies to draw the eye to, and the body through, his buildings. For example, he often minimised the division between the interior and the surrounding landscape by using corner glazing (without mullions), large expanses of glass in public areas, continuous ceiling-eaves and reflecting pools. Neutra also frequently used silver paint on surfaces in an attempt to "dematerialise" certain elements, so as not to distract the eye from the dominant vistas and paths he wished to emphasise. As Lamprecht [2000] observes, "[t]he silver appears only in those places where the sightline is affected" [34]. By controlling the built form in this way, Neutra argued that he could control the experience of the house through sightlines and paths. In combination, the vistas and paths created in the 
plans represent a way of developing an understanding of each building through the process of discovery. Assuming that Neutra was able to embed these design values in the planning of his houses, it should be possible to observe, measure and even quantify the role played by vistas and paths in his designs.

The Axial Line method is one approach that can be used to identify and measure sight lines, as a precursor to developing an understanding of the experience of space through movement. In the next section an overview of this method, including recognition of several limitations, is provided.

\section{Axial Line Analysis}

Axial Line analysis was developed by Space Syntax researchers for investigating architectural and urban plans. It was first formulated by Hillier and Hanson [1984] as a means of gaining insight into the social drivers and social impacts of spatial configurations. The Axial Line method has been widely applied in urban analysis [Hillier 1996; Read 1996; Desyllas 2000] and in the analysis of large buildings [Peponis et al. 1997; Shpuza and Peponis 2008; Rashid et al. 2009]. It has only rarely been applied to residential structures although several precedents exist [Hillier and Hanson 1984; Hanson 1998].

Space Syntax researchers traditionally approach architecture from a topological perspective-which is focussed on the relationships between spaces-rather than a geographic perspective-where spatial dimensions take precedence [Hillier 1996; Hanson 1998]. In order to accommodate this position, the architectural plan that is being analysed is first stripped of any dimensional information. Thereafter a range of different methods may be applied to the plan to draw out its properties. Amongst the most well known methods are Justified Plan Graph analysis and Axial Line analysis [Ostwald 2011]. The former of these is only concerned with the configuration of space from the point of view of connectivity; the latter is focussed on identifying and analysing vistas and paths through space. Both methods commence by converting the architectural plan into a diagram of "convex space"; a representation of visually defined space.

The Axial Line method generalises the plan into the map of the fewest and longest straight lines which can be drawn on the plan and will fulfil several criteria; the two most important of which are that they account for all non-trivial spatial features in the plan and that they connect with another line. Each of these lines is therefore both a defined view through a building and a path that can be traversed across a plan. The axial map is, in effect, the plan converted into a network diagram of nodes and edges which can be analysed to identify various relative qualities about the network including depth, integration and control. Because the method is optimised to identify the fewest and longest vistas or paths, it effectively offers a way of investigating the significance of visual permeability in Neutra's domestic architecture. Axial Line analysis has similarities to isovist analysis and view-shed analysis [Benedikt, 1979; Benedikt and Burnham, 1985; Batty, 2001] which are all concerned with the volume of space that can be seen from fixed points or points along a fixed path.

Despite the apparent clarity of the approach, there are multiple, alternative procedures for generating an axial map [Peponis et al. 1997; Batty and Carvalho 2003; Turner et al. 2005]. Indeed, this is one potential limitation of the method; that there is no single, ideal Axial map, rather there are a range of potentially valid maps [Batty and Rana 2004]. The second potential issue with the method is that it may be over-sensitive to minute changes in plan geometry 
[Ratti 2004]. Notably, both of these criticisms relate more to the repeatability of the method (its capacity to be replicated) than they do to its mathematical basis. The interpretation of the results has also been the subject of criticism because the method quantifies certain properties that are normally only understood qualitatively [Montello 2007]. This criticism is a useful reminder that the results of the method-and of the present paper-should only be used relatively; that is, for comparison between similarly produced sets of results.

The Axial Line method is described in many publications [Hillier and Hanson 1984; Hillier 1996] and the mathematics of graph theory, as applied in Space Syntax, has also been extensively published [Hanson 1998; Ostwald 2011]. The following properties or values, as determined by the method, are used in the present research.

\section{Depth}

- The number of lines that must be traversed to reach a particular space, from every other space, is a measure of the Total Depth $(T D)$ of that space in the plan. The Mean Depth $(M D)$ of lines in a plan can be determined to classify those that are shallow or deep, relative to the entire building.

\section{Asymmetry}

- Relative Asymmetry $(R A)$ is a measure of the degree of isolation of a line in relation to the rest of the system. A determination can also be produced of the Asymmetry of a line, relative not only to its plan, but also to a benchmark, or optimal, configuration; this is known as Real Relative Asymmetry ( $R R A)$. RRA is useful because it allows a comparison to be constructed between multiple buildings with different scale spatial configurations.

\section{Integration}

- Integration $(i)$ is a measure of the distance in steps-meaning direction changes-from a single line to every other line in the system. A higher $i$ value suggests that a line is more accessible to every other line in the system than one with a lower $i$ value. Integration in axial maps has been shown to closely correlate to the level of pedestrian use and the number of social encounters occurring in individual spaces [Hillier et al. 1993; Hillier 1996].

\section{Intelligibility}

- Axial line analysis can also be used to develop a measure of the "intelligibility" of a plan [Peponis et al. 1990; Hillier 1996; Haq and Girotto 2003]. Intelligibility is a measure of the global-local relationships; how well the entire configuration is understood by traversing the components of the configuration. The intelligibility measure is developed from a scatter graph of the connection and integration values of each line. The logic behind this process is that integration represents a global measure of the connectivity of a given space to all other spaces in the system. The number of connections the line makes represents how much of a configuration can be seen from each line; therefore the relationship between these measures indicates how intelligible a plan is. The higher the correlation 
of points the closer the scatter graph conforms to a $45^{\circ}$ line and the more intelligible the system.

\section{Step Distance}

- Step distance is a measure of the minimum number of direction changes encountered along a path between the most public and most private spaces in a design. Hanson [1998] uses step distance as a comparative measure of social separation.

\section{Methodological Considerations}

Despite the Axial Line method being widely used, there are several features of it that must be defined before each application. The most important of these is the process of generating the map. In order to ensure consistency and repeatability, UCL Depthmap software has been used for the analysis of the five designs. This software was originally programmed to assist in isovist or view-shed analysis before further features, including axial line analysis, were added [Turner 2004]. Importantly, this software calculates integration using $R R A$ values, which means that the results are relativised for direct comparison between different houses.

Before the software analysis can begin, each of the building plans must be digitised. For the present research new drawings were prepared using a combination of Neutra's original working drawings, published plans and photographs of the completed houses. Thereafter, several decisions need to be made about how the drawings are processed by the software. The general principle used to inform each of these decisions is that Axial Line analysis is concerned with the relationship between visibility and accessibility. As Koch [2010] explains, "one of the most pervasive, effective, and powerful means through which architecture formulates social significance and social meaning is through the separation of accessibility and visibility" [13].

Starting with the larger scale decisions; the boundaries of each plan were typically "cropped" close to the house to maintain the analytical focus on habitable spaces. This means that while exterior paths and driveways in Neutra's designs can often extend a long distance from the house, only those close to the buildings, and clearly "spatially defined", were included. In this case-and because of the importance of outdoor "rooms" and "corridors"-"spatially defined" was taken to mean any hard-paved or similarly defined area that is delineated by at least two walls.

The next decision is which internal spaces to include in the analysis. In this instance a number of spaces not contributing to the social function of each building were excluded. These include dumbwaiters, plant rooms and storage areas that were either too small for human inhabitation or not designed for any social use. Similarly, any built-in furniture was treated as an unnavigable obstacle while all doors were assumed to be open. Following the principle of an axial line simultaneously representing both vision and access, glazed walls were treated as solid elements, as were pools and water features, while small columns (less than $250 \mathrm{~mm}$ in section), which would impose minimal impact on circulation and views, were omitted.

For the present research stairs were divided into two categories; those which do not interrupt the spatial cognition of a traversing user and those that do. In the first category are small sets of stairs, with four or fewer risers, that are part of a larger space and do not unduly disrupt 
the direct visual and physical connection across that space. In the second category are stairs with five or more risers, which are treated as a separate spatial unit requiring a dedicated axial line. Landings were considered part of any stair set connected to them; thus a single landing could be simultaneously considered as part of both types of stair. Where a dedicated line was required to connect multiple levels this section of the plan was split as necessary. Where no axial line existed that ran the entire length of a stair, one was added to complete the circulation paths and a line connecting this to the remainder of the network also added. The curved lines that appear in some of the maps signify a level change in an axial line; this representation follows the convention of Hanson [1998] and has no impact on the mathematical result.

For each house an aerial perspective view is provided along with a plan annotated to identify the functional uses of different spaces (table 1). The first numbered bedroom in the plan is the master bedroom. Maid's and chauffeur's bedrooms, guest bedrooms and servant spaces (including small living rooms for servants) are differentiated from the main family spaces in the text, but not in the annotations which are simply numbered in accordance with their base function.

Table 1: Key to Plan Annotations

\begin{tabular}{|l|l|}
\hline C & Courtyard \\
\hline CP & Car Parking \\
\hline T & Terrace \\
\hline GL & Gloriette \\
\hline E & Entry \\
\hline H & Hallway \\
\hline P & Porch \\
\hline
\end{tabular}

\begin{tabular}{|l|l|}
\hline K & Kitchen \\
\hline L & Living \\
\hline D & Dining \\
\hline G & Gallery \\
\hline ST & Studio \\
\hline LB & Library \\
\hline BI & Master Bedroom \\
\hline
\end{tabular}

\begin{tabular}{|l|l|}
\hline B2... & Secondary Bedrooms \\
\hline b1... & Bathrooms \\
\hline DR & Dressing \\
\hline S & Storage \\
\hline LD & Laundry \\
\hline SV & Service area \\
\hline CR & Change rooms \\
\hline
\end{tabular}

An axial map is reproduced for each of the five houses, with the lines differentiated to show the top-third, most integrated, the middle third, and the lowest third, least integrated. The most integrated line is numbered, along with the line that is closest to the mean and the one which is least integrated (figure 1). If two or more of these lines have equal $i$ values, then they are all indicated. Rather than providing a full table of results for every line for every house (leading to over 200 lines of data), only the top three, middle three and lowest three lines, based on integration values, are published. However, because multiple lines may have identical $i$ values, several of the tables contain more than three results. The high, mean and low results at the base of each column in the tables is for the complete set of lines.

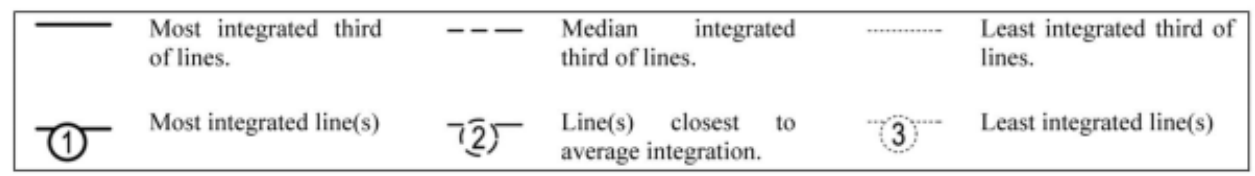

Figure 1: Key to Axial Maps 


\section{Analysis and Results}

\section{Kaufman Desert House, (1946-47)}

The Kaufmann Desert House is sited at the base of Mount San Jacinto in Palm Springs (California); a location which, when the design was commissioned, was a sparsely populated desert landscape. The house features a central living area from which four major functional wings radiate. This pinwheel configuration has more public spaces at the core and more private or functional zones (like the garage) in the wings (figure 2). Significantly, the rooms in three of the wings are only accessible by way of external circulation paths. Described by Lamprecht [2000] as Palm Springs "first modernist grand villa" [179] and a "social extrovert" [179], the house "subsequently became the chief d'oeuvre in a suburban townscape" [Hines 1982, 201].

The plan of the Kaufman Desert House features two orthogonal axes; the first linking the garage and entry to the guest rooms and the second between the maid's room and the bedrooms. Centred above the living area is an upper level gloriette; a semi-external living space (figure 3). A visual analysis of the axial map of the house plan reveals a number of significant circulation loops including one through the master bedroom. All of these loops, to some extent, rely on external circulation. This reliance is not surprising given that it is impossible to inhabit this house, or at least use its functional zones as planned, without using covered, external paths (figure 4).

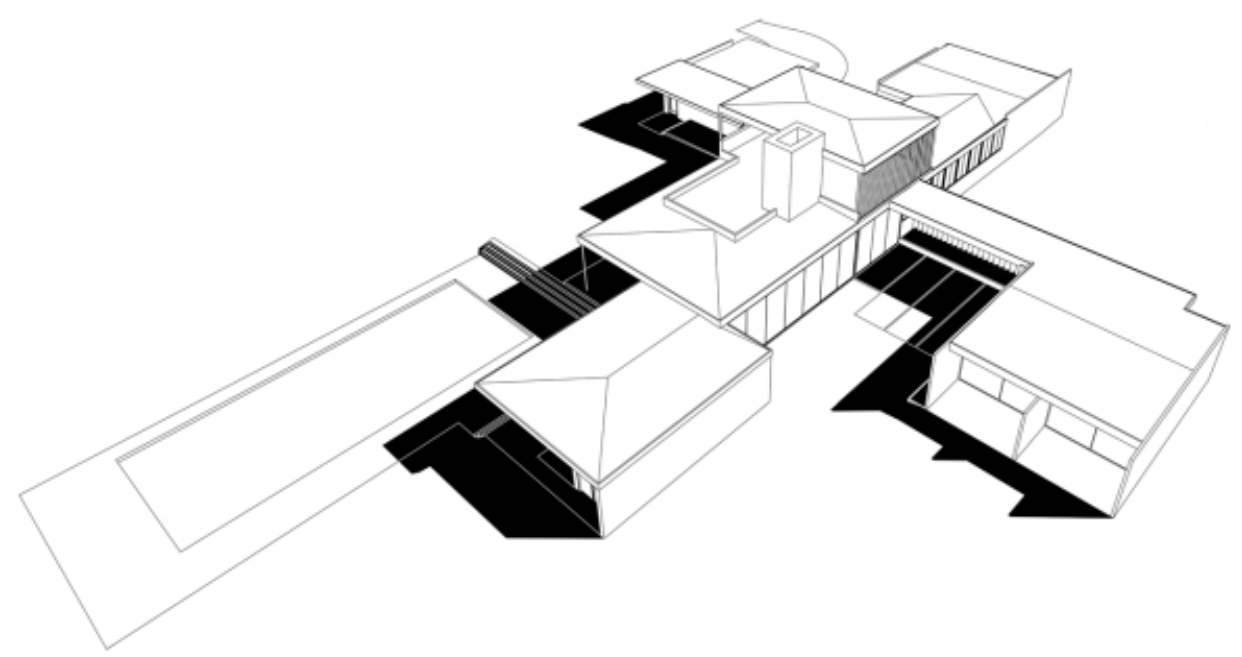

Figure 2: Kaufman Desert House, Aerial Perspective View 


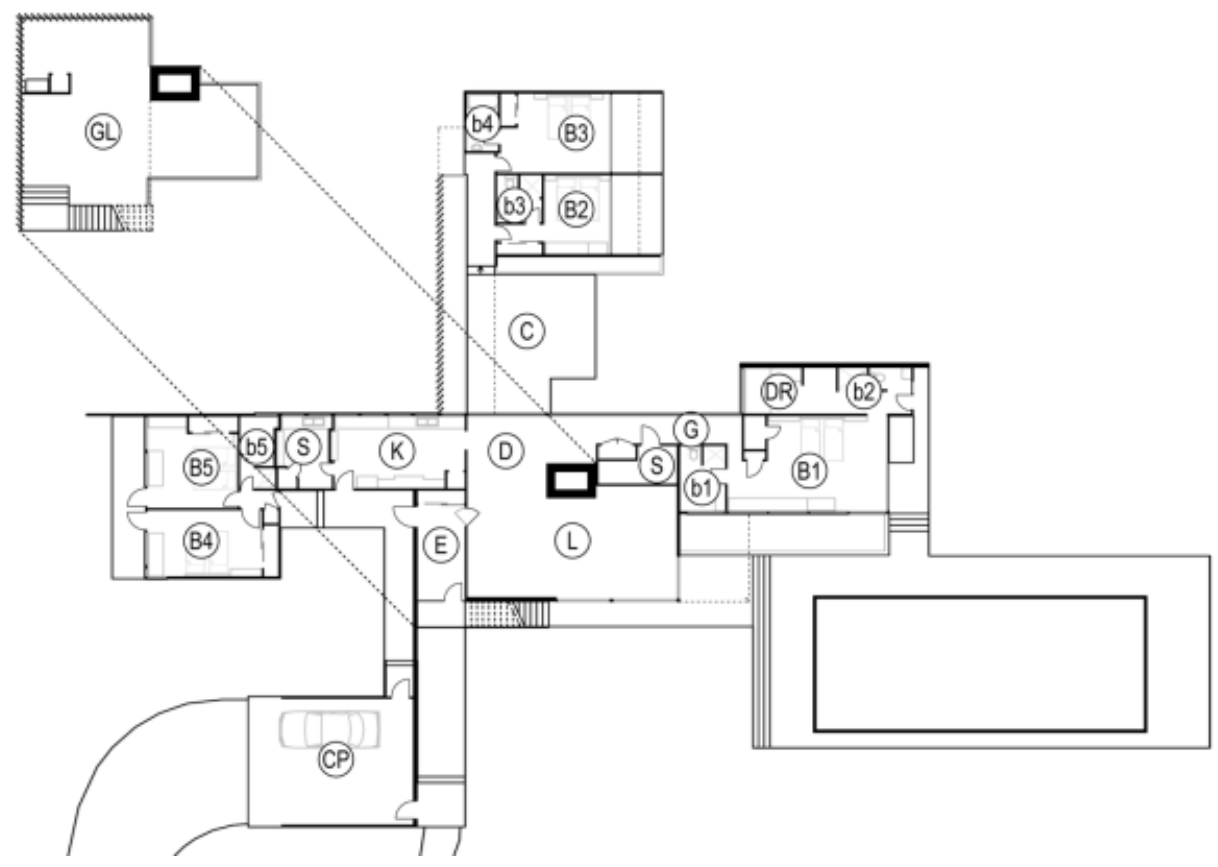

Figure 3: Kaufman Desert House, Annotated Plan

The axial map for the Kaufmann House identifies 33 lines, the longest and most integrated of which cross in the living room (table 2$)$. The most integrated line $(i=3.27)$ runs from the second Maid's bedroom (B5), along an exterior corridor, though the entry foyer, the living room and to the pool. The line with the mean integration value commences in the first Maid's bedroom (B4) before passing along an exterior corridor, to the dining room. The gloriette, which is connected to the house by way of a single set of external stairs that is accessed via the pool, contains the most segregated vista in the design $(i=0.68)$. The complete set of results also confirms that the Kaufman Desert House is flexible and adaptive when external circulation connections are included and highly inflexible when they are not.

Only two changes of direction are required to progress from the formal entrance to the master bedroom; a result which is also the same for three of the four remaining bedrooms. The second Maid's bedroom only has a single direction change from the entry. This means that each of the deeper bedrooms is at least partially visible with only a single direction change after entering the building. This implies either a relatively low privacy threshold in the house or a high degree of visual permeability.

The data suggests that the Kaufman Desert House is very intelligible; as evidenced by the strong, almost $45^{\circ}$ trend-line. Overall, there is a high degree of correlation (87\%) between integration and connectivity (figure 5). This result occurs because there are several highly integrated, long, lines which pass through the centre of the plan along with an overall shallow planning strategy for the house $(M D=2.8)$. 


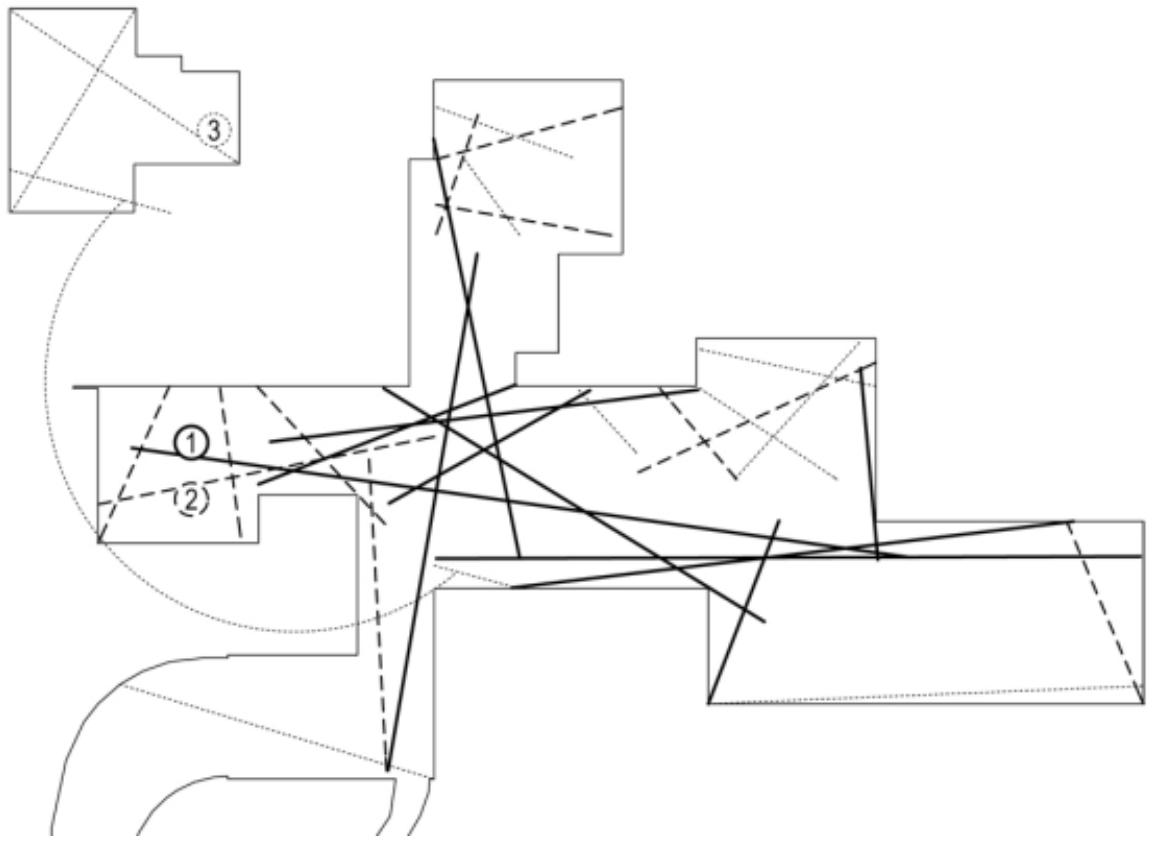

Figure 4: Kaufman Desert House, Axial Map

Table 2: Kaufman Desert House, Results

\begin{tabular}{|l|l|l|l|l|l|l|}
\hline & MD & RA & RRA & Integration & Line Length & Connectivity \\
\hline \multirow{3}{*}{$\begin{array}{l}\text { Lowest three } \\
\text { values }\end{array}$} & 4.90625 & 0.25201613 & 1.471236 & 0.67970061 & 13217.801 & 1 \\
\cline { 2 - 7 } & 3.9375 & 0.18951613 & 1.1063695 & 0.90385723 & 11468.753 & 2 \\
\cline { 2 - 7 } & 3.875 & 0.18548387 & 1.0828297 & 0.92350626 & 4547.7354 & 1 \\
\hline \multirow{3}{*}{$\begin{array}{l}\text { Median three } \\
\text { values }\end{array}$} & 2.875 & 0.12096774 & 0.70619327 & 1.4160429 & 5721.0405 & 3 \\
\cline { 2 - 7 } & 2.875 & 0.12096774 & 0.70619327 & 1.4160429 & 9628.5596 & 3 \\
\cline { 2 - 7 } & 2.875 & 0.12096774 & 0.70619327 & 1.4160429 & 6052.48 & 4 \\
\cline { 2 - 7 } & 2.75 & 0.11290322 & 0.65911371 & 1.5171889 & 7499.2041 & 2 \\
\cline { 2 - 7 } & 2.75 & 0.11290322 & 0.65911371 & 1.5171889 & 8289.5205 & 2 \\
\hline \multirow{4}{*}{\begin{tabular}{l} 
Highest three $i$ values \\
\cline { 2 - 7 }
\end{tabular}} & 2.0625 & 0.068548389 & 0.4001762 & 2.4988992 & 21077.938 & 10 \\
\cline { 2 - 7 } & 2.03125 & 0.066532262 & 0.38840631 & 2.5746236 & 21867.721 & 9 \\
\cline { 2 - 7 } & 1.8125 & 0.052419353 & 0.30601707 & 3.2677915 & 38547.859 & 14 \\
\hline
\end{tabular}

\begin{tabular}{|l|l|l|l|l|l|l|}
\hline Min & 1.8125 & 0.052419353 & 0.30601707 & 0.67970061 & 4081.1396 & 1 \\
\hline Mean & 2.84469697 & 0.119012708 & 0.694780048 & 1.627964315 & 13669.57778 & 4.424242424 \\
\hline Max & 4.90625 & 0.25201613 & 1.471236 & 3.2677915 & 38547.859 & 14 \\
\hline
\end{tabular}

\begin{tabular}{|l|l|}
\hline Steps to main bedroom & 2 \\
\hline Total number of lines in map & 33 \\
\hline
\end{tabular}




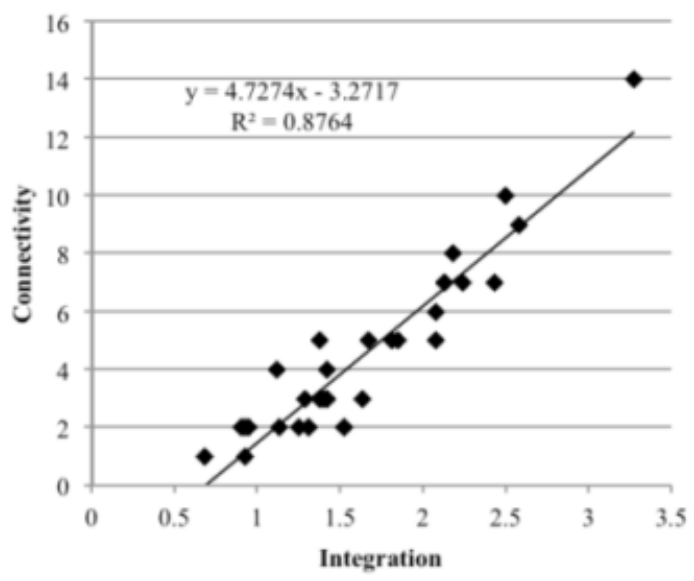

Figure 5: Kaufman Desert House, Intelligibility Graph

\section{Tremaine House (1947-48)}

Neutra was working on the Tremaine house concurrently with the Kaufmann Desert House and both share pinwheel plans, centrally located social spaces and masonry walls grounding the structure, perceptually at least, in the landscape (figure 6). The Tremaine House, which was designed as a permanent residence for a couple and their three children, has more than 30 rooms, including a basement level (figure 7). As is the case with the Kaufman Desert House, in the Tremaine House a small number of long lines run through the centre of the elongated pinwheel, forming connections between separated wings of and connecting many spaces. However, in the Tremaine House non-trivial circulation loops exist without requiring external circulation, offering a greater degree of flexibility in space use (figure 8).

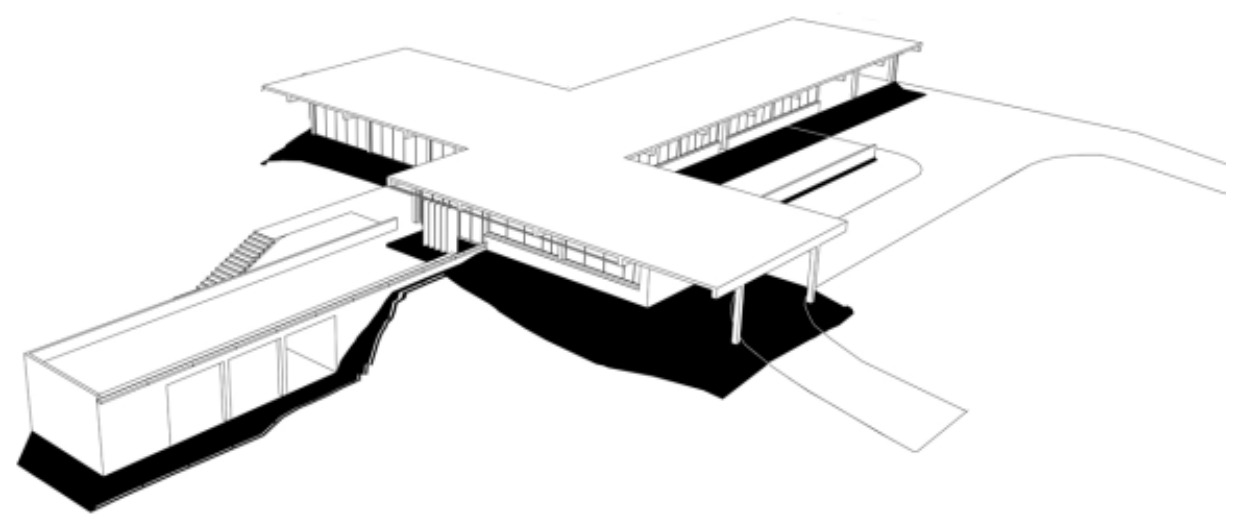

Figure 6: Tremaine House, Aerial Perspective View 


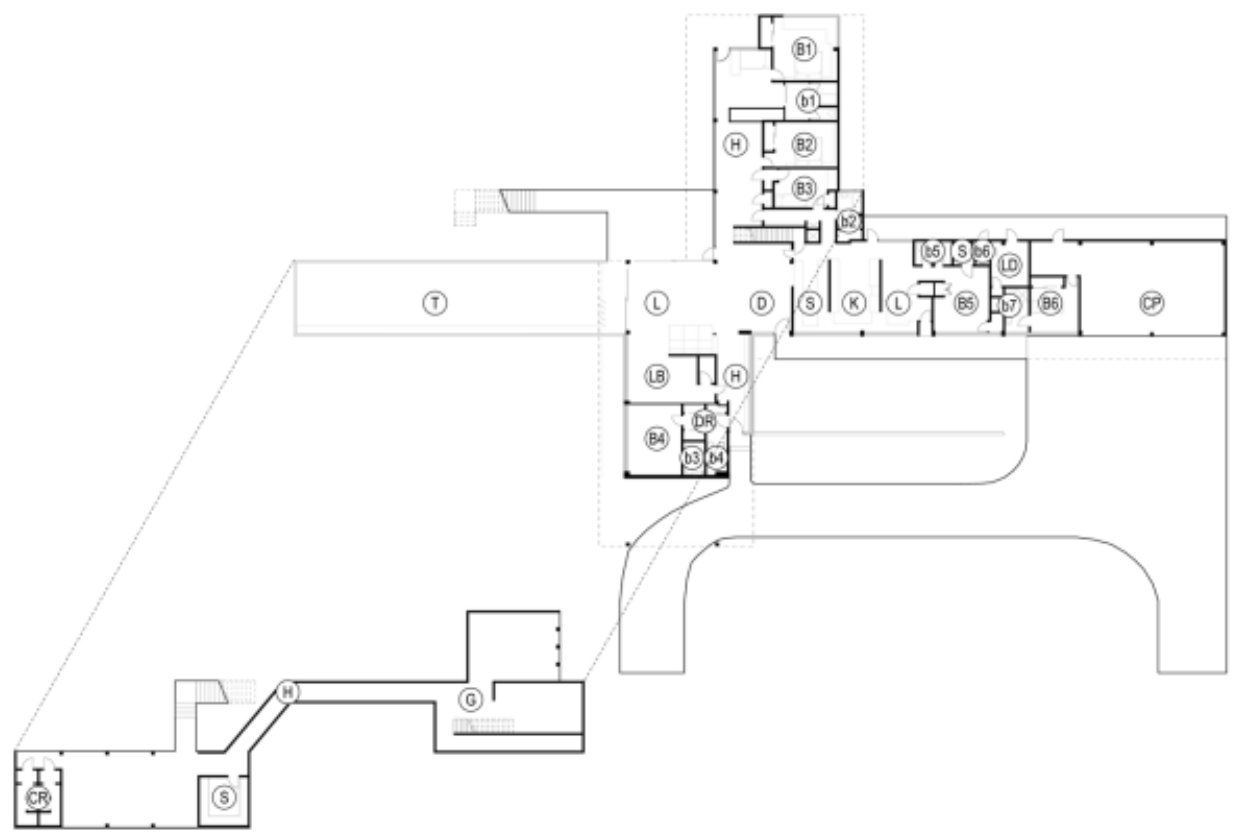

Figure 7: Tremaine House, Annotated Plan

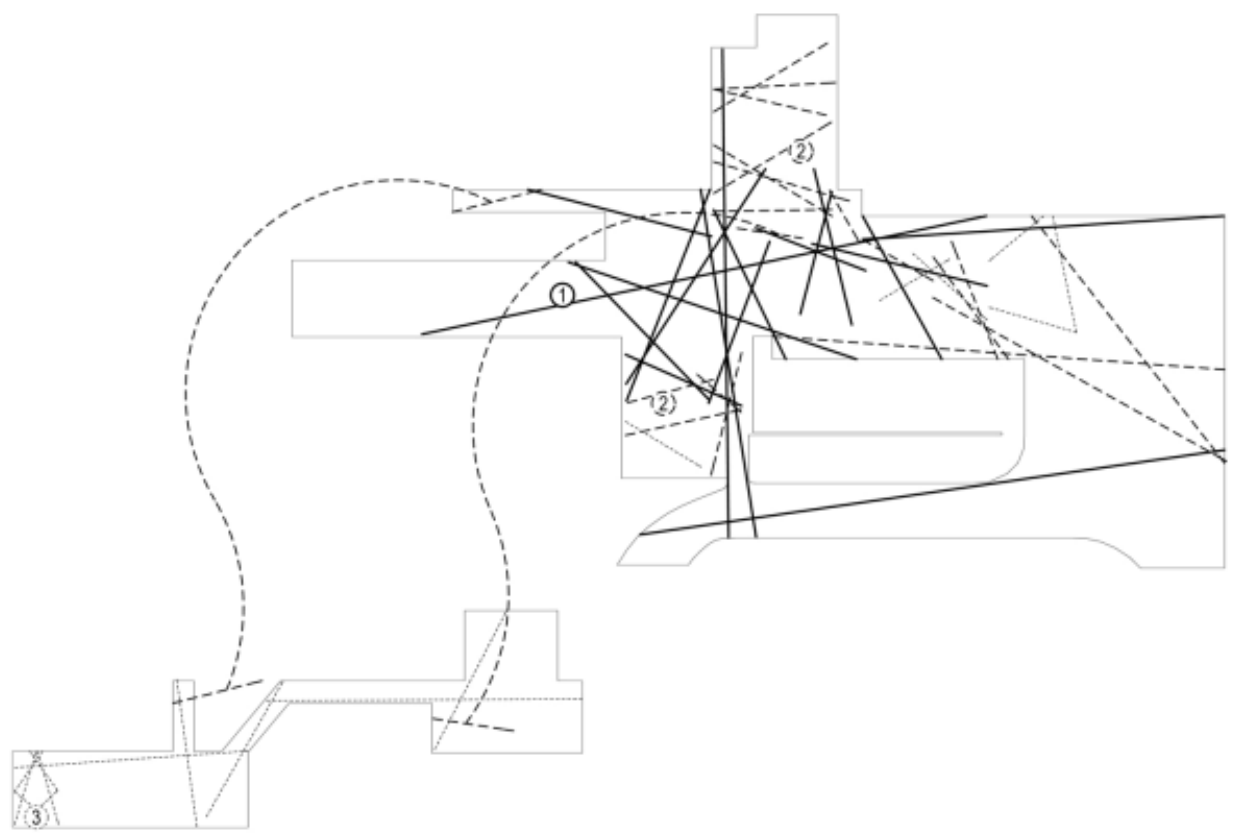

Figure 8: Tremaine House, Axial Map 
The axial map for the Tremaine House reveals that 56 lines are required to produce a valid analysis (table 3 ). The mathematical processing of the data identifies that the longer lines crossing the central living spaces are the most integrated in the house $(2.11<i<2.30)$ and the third highest integration value is for a line crossing the formal entrance. Conversely, the lines in the basement level are among the least integrated in the design $(0.58<i<1.0)$. The line with the highest integration passes through the terrace, the living room, the kitchen and the exterior circulation. The lines that are closest to the mean for integration pass through, respectively, the hall and the bedroom 2 , and the library and the filing room. The lowest integration lines are for the change rooms in the basement level (which were intended for a pool that was never built). The Tremaine House is the least intelligible of the five Neutra houses analysed in the present paper, having both the weakest correlation between line connectivity and integration and the least balanced (or furthest from 45) trend-line where the axis are scaled to give a square graph (figure 9). This house also has the highest mean and total depths of the five houses.

Table 3: Tremaine House, Results

\begin{tabular}{|l|l|l|l|l|l|l|}
\hline & MD & RA & RRA & Integration & Line Length & Connectivity \\
\hline \multirow{2}{*}{$\begin{array}{l}\text { Lowest } \\
\text { three } i \\
\text { values }\end{array}$} & 6.7090907 & 0.21144781 & 1.7038453 & 0.58690774 & 1992.0631 & 2 \\
\cline { 2 - 8 } & 6.7090907 & 0.21144781 & 1.7038453 & 0.58690774 & 1993.1252 & 2 \\
\cline { 2 - 8 } & 5.7636366 & 0.17643097 & 1.4216799 & 0.70339328 & 5314.2666 & 4 \\
\cline { 2 - 8 } & 5.7636366 & 0.17643097 & 1.4216799 & 0.70339328 & 5314.2012 & 4 \\
\hline \multirow{2}{*}{$\begin{array}{l}\text { Median } \\
\text { three } i \\
\text { values }\end{array}$} & 3.5090909 & 0.092929296 & 0.7488237 & 1.3354278 & 23184.82 & 5 \\
\cline { 2 - 8 } & 3.4727273 & 0.091582492 & 0.73797119 & 1.3550664 & 9551.1729 & 3 \\
\cline { 2 - 8 } & 3.4727273 & 0.091582492 & 0.73797119 & 1.3550664 & 6084.0195 & 4 \\
\hline \multirow{2}{*}{$\begin{array}{l}\text { Highest } \\
\text { three } i\end{array}$} & 2.5818181 & 0.05858586 & 0.47208452 & 2.1182647 & 33713.641 & 18 \\
\cline { 2 - 8 } & 2.5272727 & 0.056565657 & 0.45580575 & 2.193917 & 24324.986 & 12 \\
\cline { 2 - 8 } & 2.4545455 & 0.053872053 & 0.43410072 & 2.3036129 & 40290.145 & 16 \\
\hline
\end{tabular}

\begin{tabular}{|l|l|l|l|l|l|l|}
\hline Min & 2.4545455 & 0.053872053 & 1.7038453 & 0.58690774 & 1992.0631 & 1 \\
\hline Mean & 3.740909095 & 0.101515151 & 0.818008519 & 1.359771029 & 11828.17539 & 5.321428571 \\
\hline Max & 6.7090907 & 0.21144781 & 0.43410072 & 2.3036129 & 41127.52 & 18 \\
\hline
\end{tabular}

\begin{tabular}{|l|l|}
\hline Steps to main bedroom & 1 \\
\hline Total number of lines in map & 56 \\
\hline
\end{tabular}




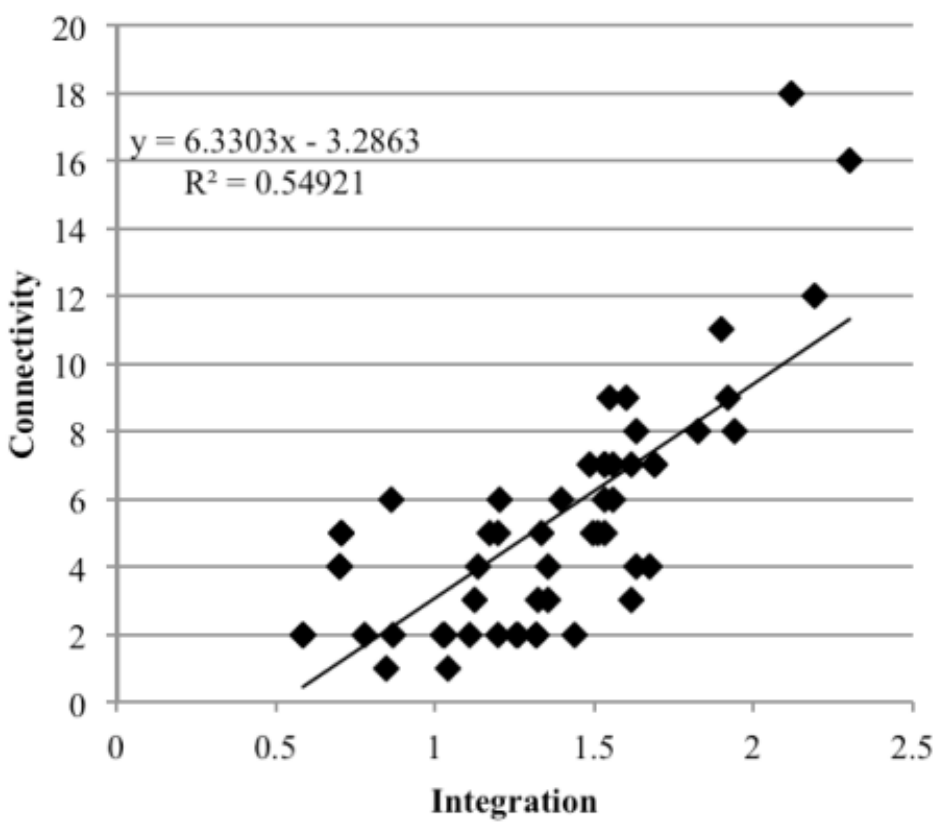

Figure 9: Tremaine House, Intelligibility Graph

\section{Moore House (1950-52)}

The Moore House in Ojai California deviates from Neutra's standard pinwheel planning arrangement having a more linear, dual pavilion arrangement, with all of its communal spaces to the north (figure 10). Like the Kaufmann Desert House, the guest wing and parking areas are accessible only via external circulation routes. A corridor connects communal, private and service space and is extended to become the path linking to the guest wing. The linearity of the plan led Lavin [2004] to note that "the architecture and the views it offers [...] are captured through peripheral vision" [109]. With 23 defined spaces, the Moore House is also much smaller than the Tremaine House and about the same size as the Kaufmann Desert House (figure 11). 


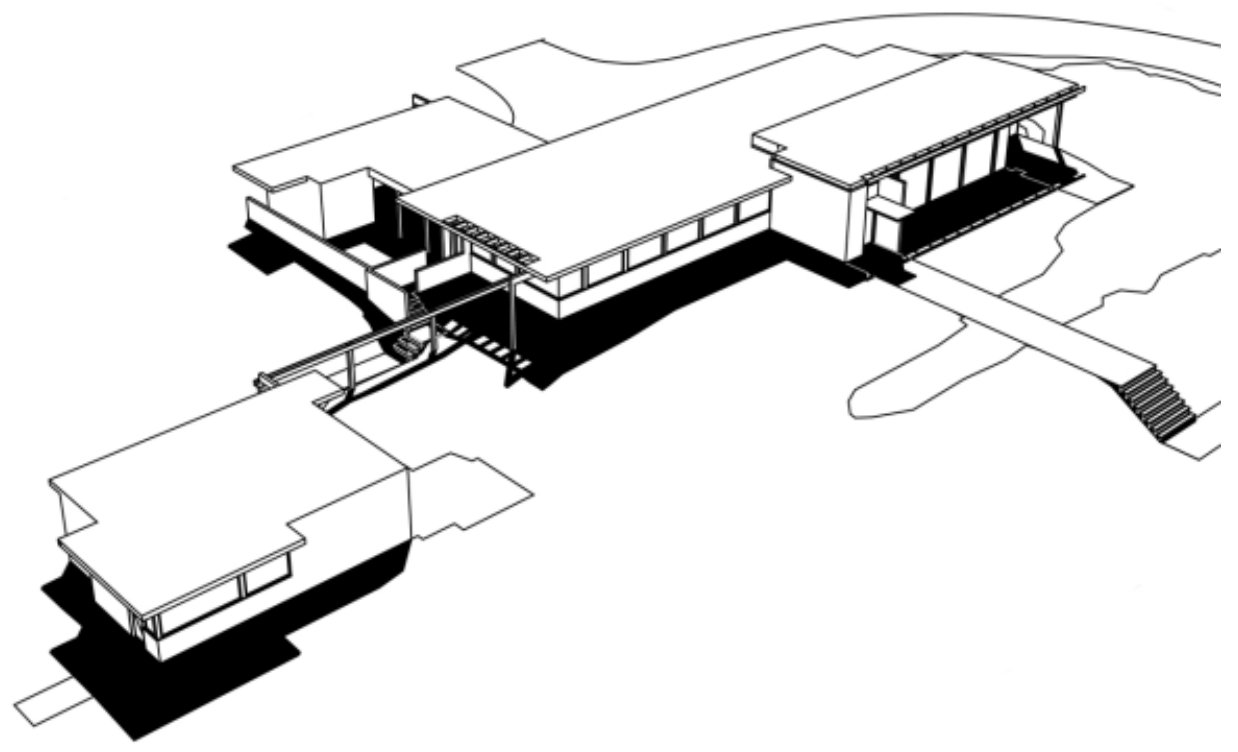

Figure 10: Moore House, Aerial Perspective View

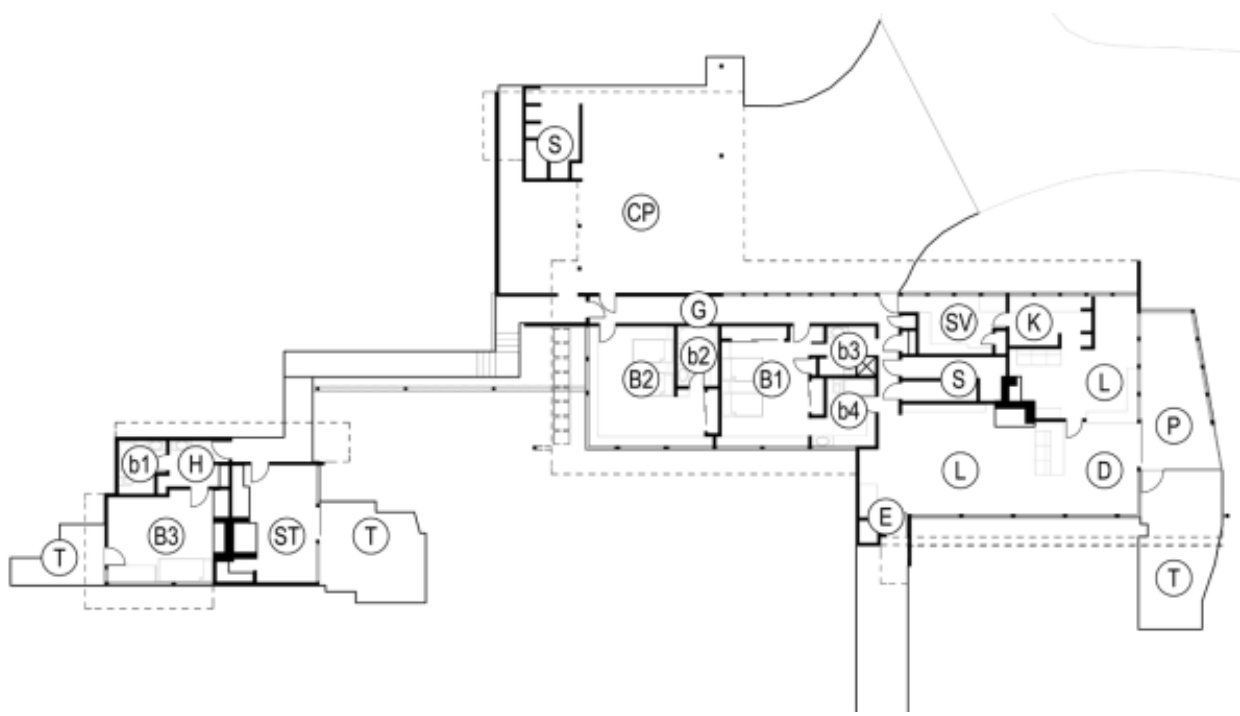

Figure 11: Moore House, Annotated Plan

An analysis of the axial map for the Moore House reveals that two long perpendicular axes form the central connections within the main house (figure 12). In this sense, the Moore House has a similar visual structure to the previous two houses, despite not having the same planning strategy. The map also reveals that three non-trivial internal circulation loops exist including, surprisingly, two involving the master bedroom and bathrooms 3 and 4 . The third loop encompasses all the house's major living areas. This property of the design suggests 
that the owners are provided with a much higher degree of flexibility than their guests and, like the Tremaine house, the master bedroom is directly accessible from the formal entrance. Only two external circulation loops exist both including the hallway.

The most integrated line in the map commences in the exterior circulation area, before passing through the hall, the service area and the kitchen. This is effectively the service backbone of the house; a structure that differs from the previous two houses which had their most integrated lines more closely associated with living spaces. The mean integrated line commences in the master bedroom (B1) and progresses through the bathroom (b4) and into the hall. The least integrated vista or path is either from the studio to the patio, or from the patio to the guest bedroom (B3).

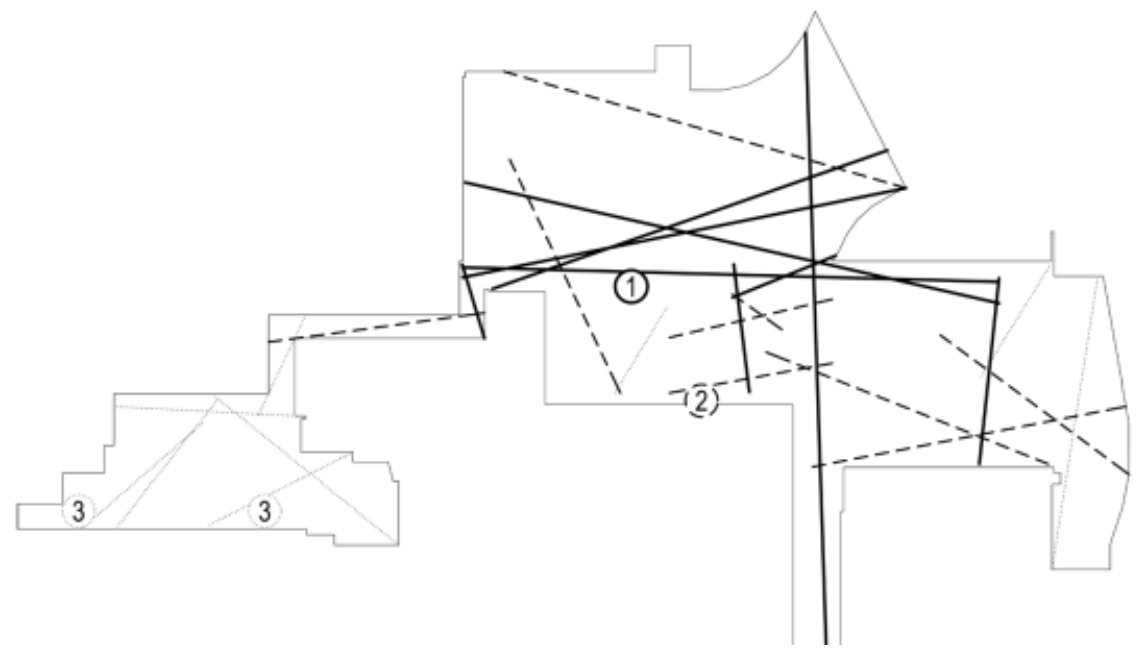

Figure 12: Moore House, Zaxial Map

The formal entrance lies on only the third most integrated line. The most and second most integrated lines intersect at a shallow angle above the upper external stair. Bedrooms in the main house are of approximately average integration $(0.79<i<1.20)$ and the living areas fall in a similar range (table 4). Like the Tremaine house this design requires only a single direction change between the formal entrance and the master bedroom (B1). This result supports the general reading of the plan, which contains a strangely centrally located master bedroom, with three alternative entry paths into it. 
Table 4: Mathematical Results from Analysis of Moore House

\begin{tabular}{|l|l|l|l|l|l|l|}
\hline & MD & RA & RRA & Integration & Line Length & Connectivity \\
\hline \multirow{2}{*}{$\begin{array}{l}\text { Lowest } \\
\text { three } i \\
\text { values }\end{array}$} & 6.1923075 & 0.41538462 & 2.1644502 & 0.4620111 & 8102.5996 & 1 \\
\cline { 2 - 8 } & 6.1923075 & 0.41538462 & 2.1644502 & 0.4620111 & 7977.4438 & 1 \\
\cline { 2 - 8 } & 5.2307692 & 0.33846155 & 1.763626 & 0.56701362 & 11600.378 & 3 \\
\cline { 2 - 8 } & 5.2307692 & 0.33846155 & 1.763626 & 0.56701362 & 8147.4399 & 3 \\
\hline \multirow{2}{*}{$\begin{array}{l}\text { Median } \\
\text { three } i \\
\text { values }\end{array}$} & 3.3461537 & 0.18769231 & 0.97801077 & 1.0224836 & 8152.3281 & 3 \\
\cline { 2 - 8 } & 3.2307692 & 0.17846154 & 0.92991191 & 1.0753707 & 15731.958 & 5 \\
\cline { 2 - 8 } & 3.2307692 & 0.17846154 & 0.92991191 & 1.0753707 & 14989.488 & 4 \\
\hline \multirow{2}{*}{$\begin{array}{l}\text { Highest } \\
\text { three } i \\
\text { values }\end{array}$} & 2.6153846 & 0.12923077 & 0.67338449 & 1.4850357 & 30626.299 & 10 \\
\cline { 2 - 8 } & 2.5384614 & 0.12307692 & 0.64131856 & 1.5592874 & 22358.23 & 7 \\
\cline { 2 - 8 } & 2.3461537 & 0.10769231 & 0.56115371 & 1.7820429 & 26545.861 & 9 \\
\hline
\end{tabular}

\begin{tabular}{|l|l|l|l|l|l|l|}
\hline Min & 2.3461537 & 0.10769231 & 0.56115371 & 0.4620111 & 2964.965 & 1 \\
\hline Mean & 3.601139563 & 0.20809117 & 1.084303416 & 1.043640657 & 12294.48708 & 4 \\
\hline Max & 6.1923075 & 0.41539462 & 2.1644502 & 1.7820429 & 30626.3 & 10 \\
\hline
\end{tabular}

\begin{tabular}{|l|l|}
\hline Steps to main bedroom & 1 \\
\hline Total number of lines in map & 27 \\
\hline
\end{tabular}

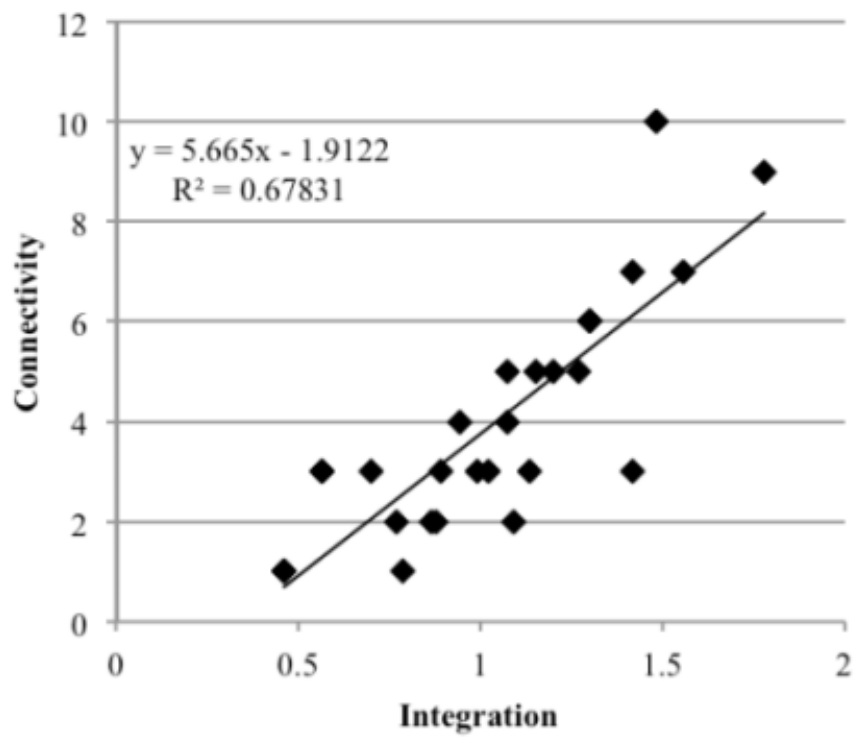

Figure 13: Moore House, Intelligibility Graph

The Moore House intelligibility graph has an $\mathrm{R}^{2}$ value of 0.67 which confirms a good correlation between integration and connectivity (figure 13). The angle of the trend-line also supports the idea that the Moore House is reasonably intelligible to its occupants. However, 
despite this general trend, a small number of scores show a large divergence between connectivity values for similarly integrated lines (especially $i \approx 1.5$ ).

\section{Kramer House, (1953)}

The Kramer House, which was designed for a physician's family, is located in the Californian desert region of Norco (figure 14). The house is approached from the south side and the entry is through a landscaped garden alongside the carport. This southern side of the house was designed to accommodate a guest room that was deliberately isolated from the main bedroom. As Lamprecht [2000] records, this guest room was intended to accommodate the busy doctor as a second-bedroom so as not to disturb his wife when he made night calls to patients. The house retains some of the pinwheel properties of the earlier plans, including a centrally located communal space, even though it is not as geometrically developed as the earlier designs (figure 15). With only 15 defined spaces, the Kramer House is one of Neutra's smaller designs of the era.

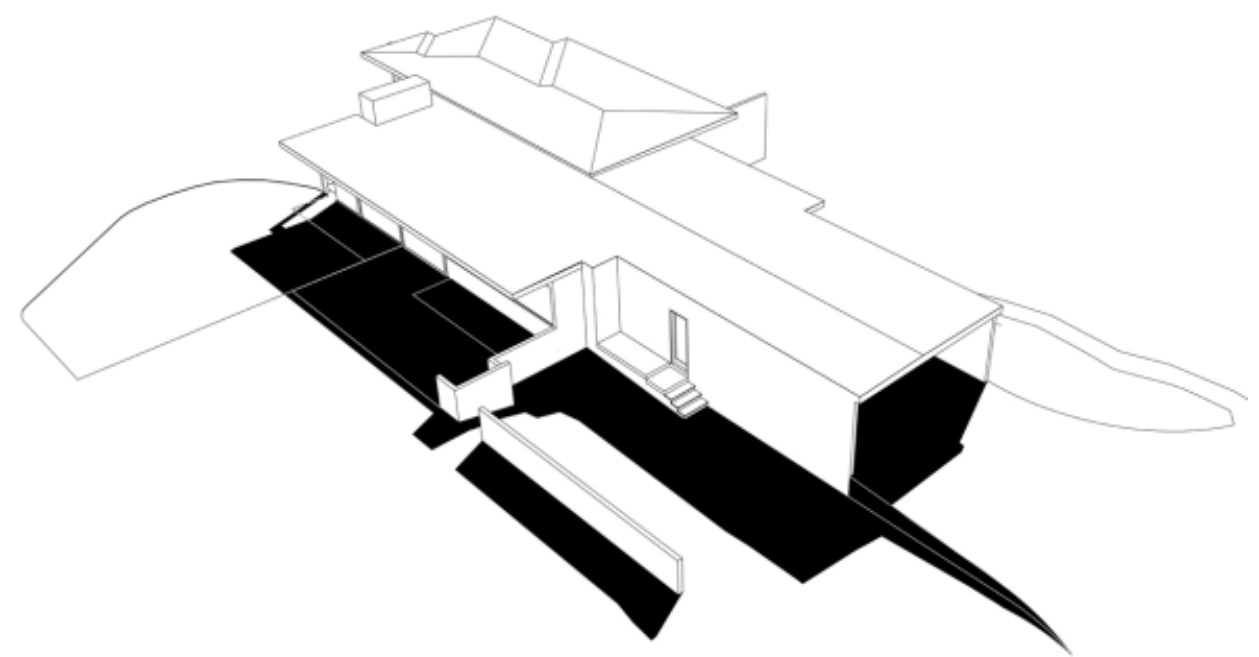

Figure 14: Kramer House, Aerial Perspective View 


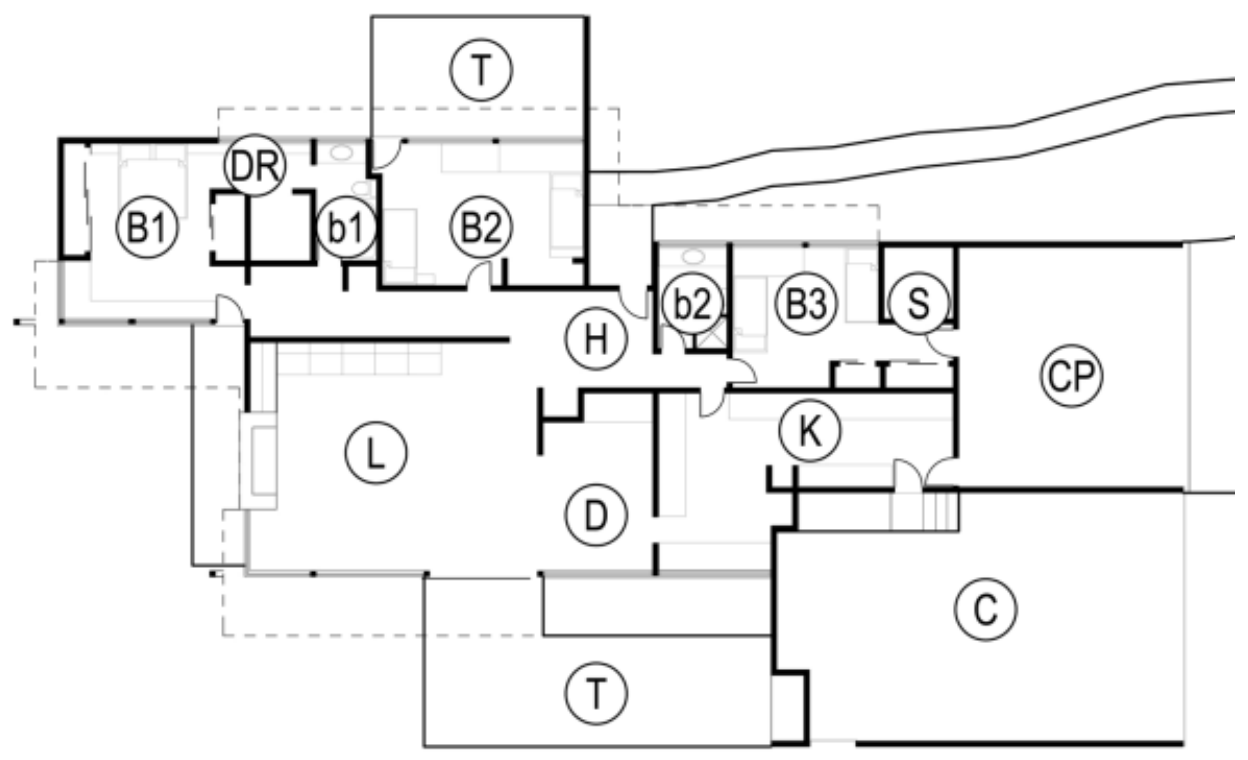

Figure 15: Kramer House, Annotated Plan

The Kramer House axial map-much like the Moore House map-reveals the longest and most integrated lines intersecting at a shallow angle in a dedicated circulation space (figure 16). Also, like the Moore House, one of these lines passes through the main living spaces at the extreme edge of the area, rather than centrally, as it does in the Kaufman and Tremaine Houses. In the Kramer House the main functional spaces are sited to the side of the circulation core and provide flexibility of space use by accommodating a secondary circulation system. Indeed, the house features separate public and private flexible zones with the main functional areas located on two of the circulation loops. The master bedroom contains the remaining loop, which is linked by only a single connection to the rest of the house. 


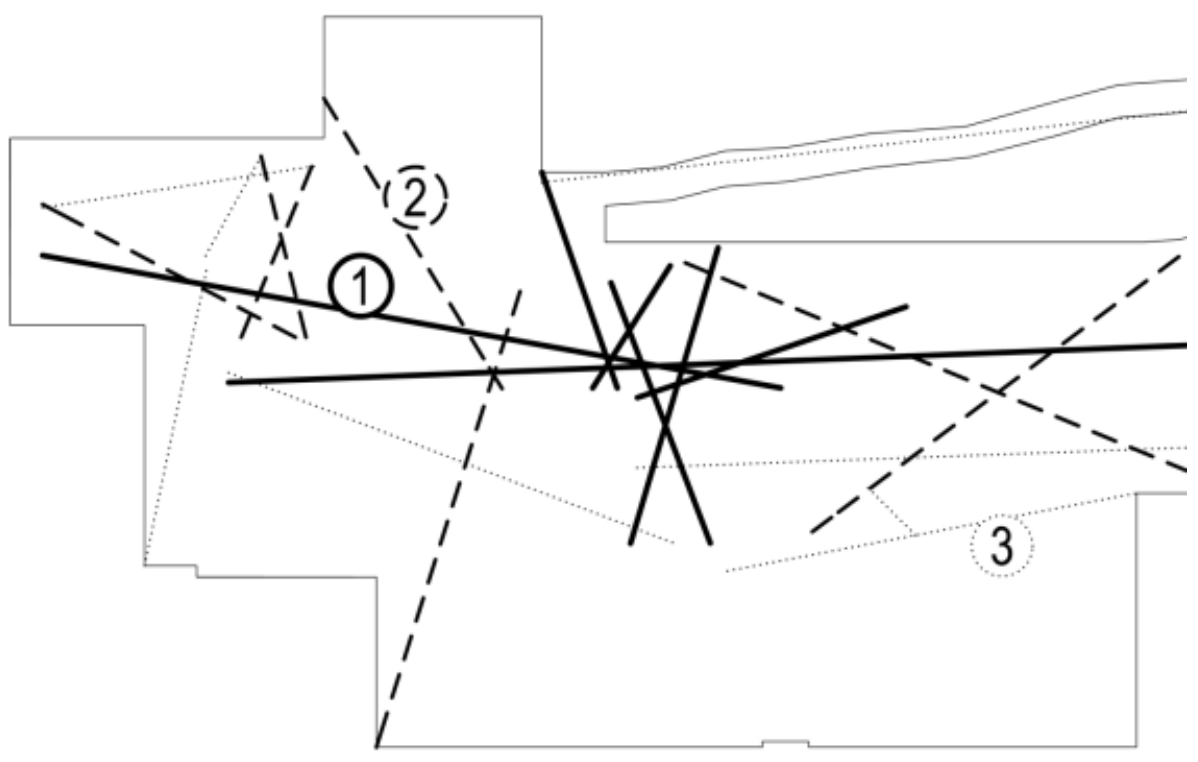

Figure 16: Kramer House, Axial Map

The axial map for the Kramer House identifies only 22 lines (table 4). Significantly, the top third most integrated lines all converge into the same hallway zone. Furthermore, the most integrated line forms the only connection between the master bedroom circulation loop and the remainder of the house $(i=3.75)$. The second most integrated line $(i=3.46)$ runs the length of the central hallway from the living room through to the garage. The least integrated paths include those to the walk-in robe $(i=1.00)$ and the courtyard $(i=0.703)$. In an interesting reflection of the brief, the same line integrates both the master bedroom (B1) and the guest bedroom (B3), separating the two, but keeping them both attached to the house in a similar social structure. This reflects the client's desire to use the guest bedroom when "oncall". From the formal entrance only a single direction change is required to reach the master and guest bedrooms. While there is geographic or dimensional distance between the entry and the bedrooms, several long, clear vistas and paths connect these spaces.

A high $\mathrm{R}^{2}$ value of 0.89 and a trend-line that is close to $45^{\circ}$ suggests that the Kramer House is highly intelligible (figure 17). This result confirms that it is possible to develop a spatial awareness of the majority of the plan by passing along a relatively small number of paths. This supports Neutra's general principle of strong spatial orientation; a quality associated with the efficient discovery of the inhabitable spaces in a plan. 
Table 5: Kramer House, Results

\begin{tabular}{|l|l|l|l|l|l|l|}
\hline & MD & RA & RRA & Integration & Line Length & Connectivity \\
\hline \multirow{2}{*}{$\begin{array}{l}\text { Lowest } \\
\text { three } i \\
\text { values }\end{array}$} & 4.047619 & 0.304762 & 1.422222 & 0.703125 & 10898.28 & 1 \\
\cline { 2 - 8 } & 3.142857 & 0.214286 & 1 & 1 & 3219.543 & 2 \\
\cline { 2 - 8 } & 3.095238 & 0.209524 & 0.977778 & 1.022727 & 1753.663 & 2 \\
\hline \multirow{2}{*}{$\begin{array}{l}\text { Median } \\
\text { three } i \\
\text { values }\end{array}$} & 2.238095 & 0.12381 & 0.577778 & 1.730769 & 13187.5 & 4 \\
\cline { 2 - 8 } & 2.238095 & 0.12381 & 0.577778 & 1.730769 & 15063.52 & 5 \\
\cline { 2 - 8 } & 2.190476 & 0.119048 & 0.555556 & 1.8 & 9005.949 & 3 \\
\hline \multirow{2}{*}{$\begin{array}{l}\text { Highest } \\
\text { three } i \\
\text { values }\end{array}$} & 1.952381 & 0.095238 & 0.444444 & 2.25 & 8140.231 & 7 \\
\cline { 2 - 8 } & 1.619048 & 0.061905 & 0.288889 & 3.461539 & 25993.31 & 11 \\
\cline { 2 - 8 } & 1.571429 & 0.057143 & 0.266667 & 3.75 & 19800.31 & 12 \\
\hline
\end{tabular}

\begin{tabular}{|l|l|l|l|l|l|l|}
\hline Min & 1.571429 & 0.057143 & 0.266667 & 0.703125 & 1753.663 & 1 \\
\hline Mean & 2.393939 & 0.139394 & 0.650505 & 1.776535 & 10121.12 & 4.363636 \\
\hline Max & 4.047519 & 0.304762 & 1.422222 & 3.75 & 25993.31 & 12 \\
\hline
\end{tabular}

\begin{tabular}{|l|l|}
\hline Steps to main bedroom & 1 \\
\hline Total number of lines in map & 22 \\
\hline
\end{tabular}

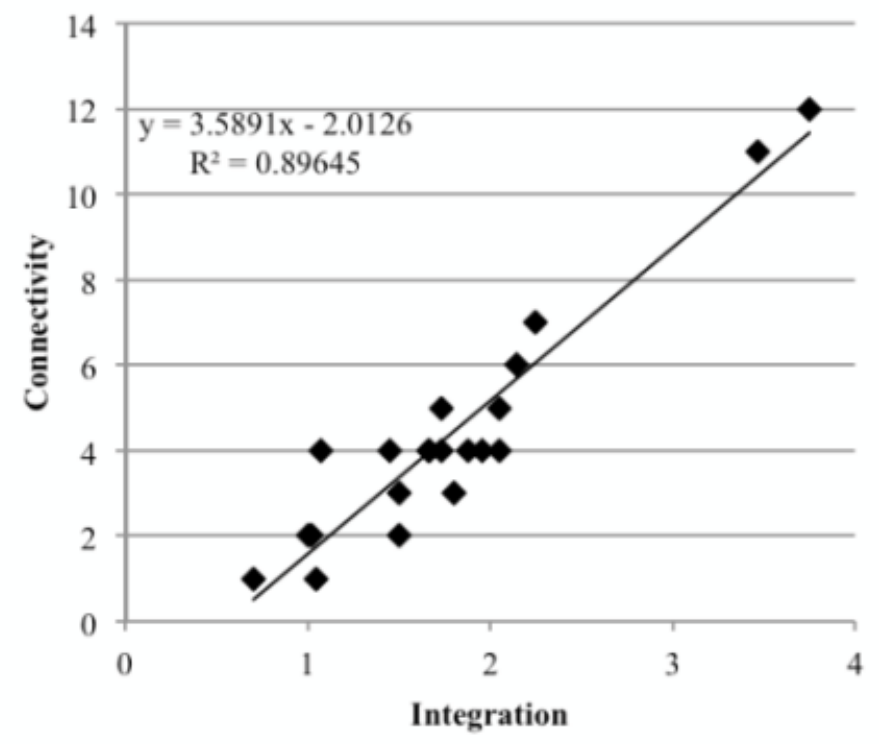

Figure 17: Kramer House, Intelligibility Graph 


\section{Oxley House, (1958)}

The Oxley House is a "modest home" [Neutra 1971,38] with only 15 defined spaces including several exterior areas. Designed for the family of a physicist, the house is located on a site overlooking the Pacific Ocean in La Jolla, California (figure 18). Originally intended to be a pinwheel plan, one wing, containing the pool and a terrace, was never constructed, leaving the house midway between the radiating and linear strategies Neutra typically employed. The entrance is by way of a stepping, angled path that connects to a covered terrace (figure 19). Once within the entry hall, the visitor is within a space with a similarly angled axis made up of a sequence of doorways which separate B1/DR, DR/L, L/H, H/B2, B2/C. This intricately planned vista (which deliberately angles across the otherwise orthogonal space of the house) is identified by the axial plan map as the most integrated, and longest, vista/path in the design; a finding which perfectly aligns Neutra's intentions with the method's findings.

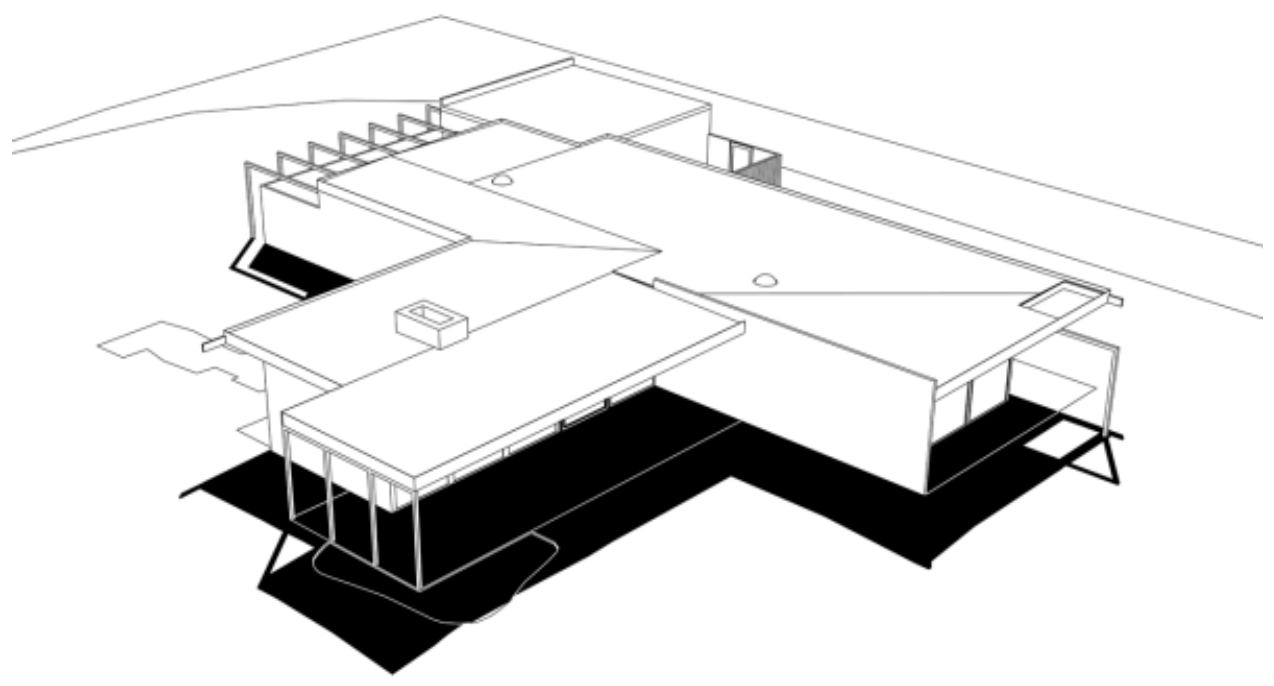

Figure 18: Oxley House, Aerial Perspective View 


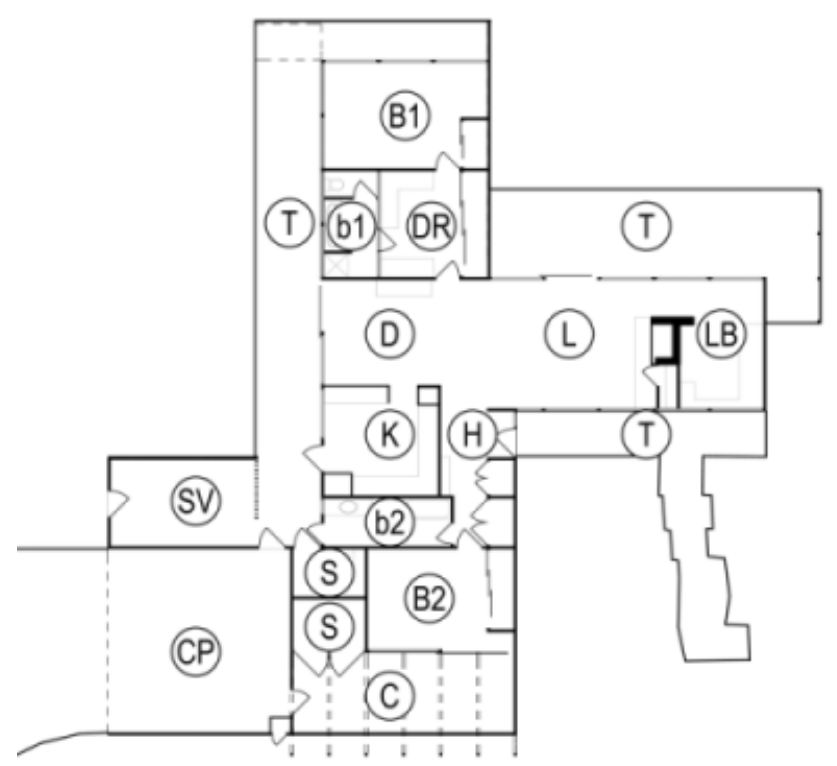

Figure 19: Oxley House, Annotated Plan

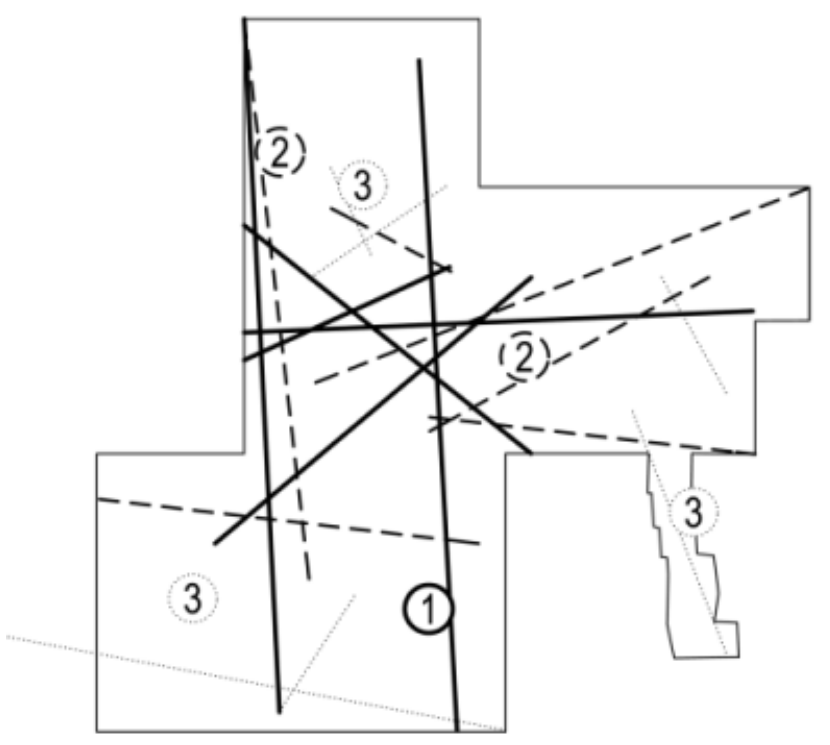

Figure 20: Oxley House, Axial Map

The axial map shows the dominance of two, almost parallel lines, one through the centre of the configuration (as previously noted) and the other connecting an external circulation zone (figure 20). These are crossed by a single perpendicular line and three angled lines. The intersection zone between the lines, which generally corresponds to the living, dining and 
terrace areas, is also the set of the most integrated lines in the house. Functional spaces supporting the living areas lie on two of the three loops offering flexibility of use for daily activities. The third loop includes the guest room and garage. Each of these circulation loops requires a degree of external circulation in much the same fashion as the Kaufman Desert House. The master bedroom, living room, hall and guest room all lie on the most integrated line $(i=5.38)$. This line is the basis of most circulation in the design, forming part of all non-trivial circulation loops (table 5). From the formal entrance only a single direction change is required to traverse the most integrated line to either of the bedrooms. Conversely, the least integrated lines are found in the master bedroom ensuite and approach path $(i=1.04)$.

Table 6: Oxley House, Results

\begin{tabular}{|c|c|c|c|c|c|c|}
\hline & MD & RA & RRA & Integration & Line Length & Connectivity \\
\hline \multirow{3}{*}{$\begin{array}{l}\text { Lowest } \\
\text { three } i \\
\text { values }\end{array}$} & 2.8235295 & 0.22794117 & 0.96078211 & 1.0408187 & 8934.4736 & 1 \\
\hline & 2.8235295 & 0.22794117 & 0.96078211 & 1.0408187 & 3260.4805 & 2 \\
\hline & 2.4705882 & 0.18382353 & 0.77482426 & 1.2906152 & 4693.9688 & 2 \\
\hline \multirow{3}{*}{$\begin{array}{l}\text { Median } \\
\text { three } i \\
\text { values }\end{array}$} & 1.8823529 & 0.11029412 & 0.46489456 & 2.1510253 & 10852.956 & 4 \\
\hline & 1.8235294 & 0.10294118 & 0.43390158 & 2.3046701 & 10653.231 & 5 \\
\hline & 1.8235294 & 0.10294118 & 0.43390158 & 2.3046701 & 19355.965 & 6 \\
\hline \multirow{3}{*}{$\begin{array}{l}\text { Highest } \\
\text { three } i \\
\text { values }\end{array}$} & 1.5882353 & 0.073529415 & 0.3099297 & 3.2265382 & 17029.711 & 9 \\
\hline & 1.5294118 & 0.066176474 & 0.27893674 & 3.5850422 & 12304.671 & 9 \\
\hline & 1.3529412 & 0.044117648 & 0.18595782 & 5.3775635 & 22429.455 & 11 \\
\hline
\end{tabular}

\begin{tabular}{|l|l|l|l|l|l|l|}
\hline Min & 1.3529412 & 0.044117648 & 0.18595782 & 1.04408187 & 2360.481 & 1 \\
\hline Mean & 1.973856211 & 0.121732026 & 0.513105848 & 2.302047222 & 12181.97768 & 5 \\
\hline Max & 2.8235295 & 0.22795117 & 0.96078211 & 5.3775635 & 23281.65 & 11 \\
\hline
\end{tabular}

\begin{tabular}{|l|l|}
\hline Steps to main bedroom & 1 \\
\hline Total number of lines in map & 18 \\
\hline
\end{tabular}

An $\mathrm{R}^{2}$ value of 0.88 and an almost $45^{\circ}$ line confirm that the Oxley House is, like most of the other Neutra houses, highly intelligible (figure 21). However the graph is marginally deceptive in that the high integration of the central line would suggest that a greater number of connections is required to more closely match the trend-line. Nevertheless, a visual review of the design reveals that the majority of internal spaces are directly observable from traversing this line, a quality which in itself would make the house intelligible. 


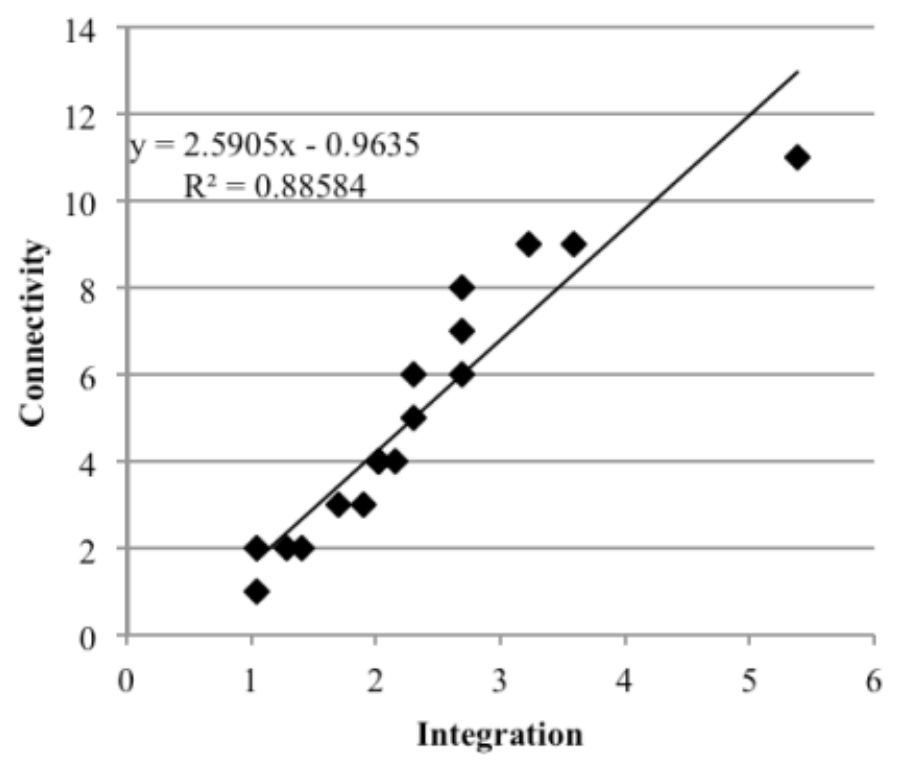

Figure 21: Oxley House, Intelligibility Graph

\section{Discussion}

All five houses have similar planning and circulation strategies; including the reliance of non-trivial circulation loops which include exterior spaces. For example, Neutra consistently includes Kitchen, Living, Dining and Garage areas on circulation loops. With the exception of the Kramer House, a portion of all of these circulation loops also includes external space. Moreover, in the case of the Kaufman and Oxley Houses, all loops require external circulation and for the former, three of the four wings are only accessible by way of external paths. In effect, the axial map confirms Neutra's stated objective, that the inhabitants of these houses are forced to interact with the environment of their respective sites.

The axial maps also demonstrate that, in each of these houses, a small number of long sightlines dominate the plan. These lines are typically located in the heart of the design and incorporate, or are adjacent to, major functional spaces. When traversing the paths defined by these sight lines, peripheral vision allows the visitor to gain additional information about the functional areas of the plan as they are passed.

While Neutra's most integrated lines cross through the geometric cores of their plans, if his architecture is dominated by long vistas, as the theory suggests, then a relatively tight integration range along with a low mean result, might be evidence for this (figure 22). Of the five houses, the larger ones typically posses the smallest range of integration values, with the smallest house (Oxley) having the widest range. Only the Moore house, which is separated into two pavilions, is the exception to the rule. However, overall, the mean integration values are all low compared to the maximum score in each house and an examination 
of the full mathematical results confirms that in each design there are a small number of highly integrated lines and a large number of lesser integrated lines.

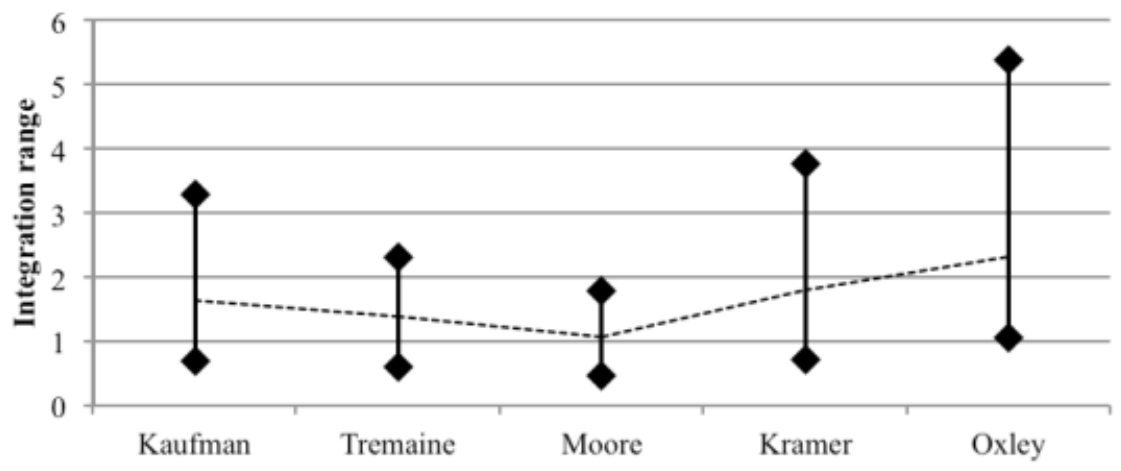

Figure 22: Relative Integration Range and Mean Integration Values for Each Residence Analysed

The shortest path from the most public space to the most private averages only 1.2 direction changes across the five designs. This confirms that the houses are all topologically shallow; a finding that is confirmed by the average mean depths of the houses; $1.9<M D<3.7$. This is evidence for a high degree of social permeability and visual clarity in the designs.

When the five intelligibility graphs are compared at the same scale their relative intelligibility can be considered (figure 23$)$. The Kramer $\left(\mathrm{R}^{2}=0.90\right)$, Oxley $\left(\mathrm{R}^{2}=0.89\right)$ and Kaufman $\left(\mathrm{R}^{2}=0.88\right)$ designs all posses very high intelligibility scores. This suggests Neutra was successful in creating strong "orienting" environments in these designs. However, Hillier [et al. 1987] states that "the mean correlation of connectivity and integration ('intelligibility') of urban layouts is $\mathrm{R}^{2}=0.68$, and this tends to decrease as the system grows" [283]. This implies that in relatively small spatial configurations intelligibility should be quite high. Interestingly, the Moore House matches this mean figure while the Tremaine house $\left(\mathrm{R}^{2}=0.55\right)$ falls significantly below, implying that, for its size, it is relatively unintelligible. 


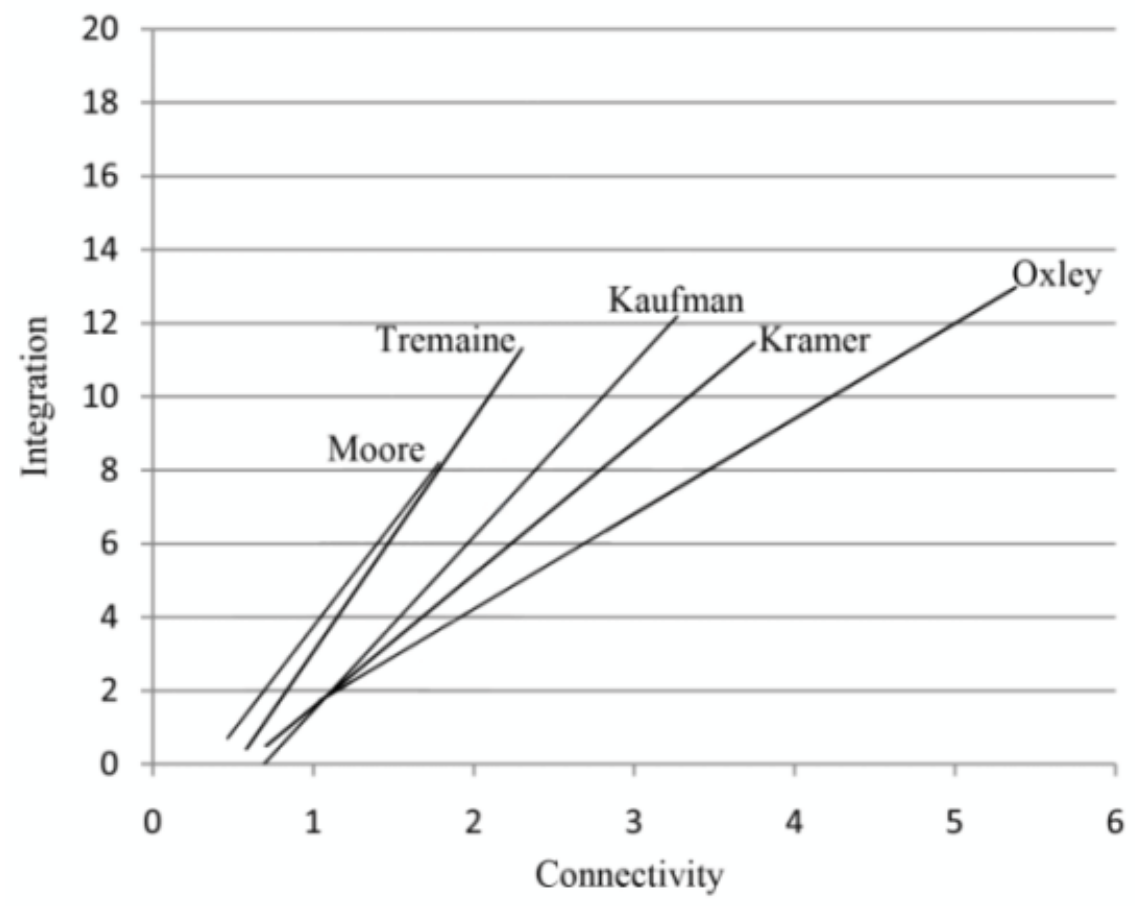

Figure 23: Intelligibility Graphs of the Five Houses Compared

\section{Conclusions}

Richard Neutra's architectural theory explicitly identifies the importance of (1) long controlled vistas, which in turn become paths (because the eye leads the body) that, (2) provide a high degree of spatial understanding or awareness. His theory also stresses the need to (3) accommodate exterior environments into the social patterns of his designs. In this paper these three facets have been examined using the Axial Line method and evidence has been found to support the importance of each of these properties. For the first of these three, all five houses feature the characteristic controlled, long, vistas and paths. For the second, three of the five houses are highly intelligible, one is in the middle to high range and one is relatively low. Finally, one of the houses cannot function without exterior circulation routes and three others require such paths to achieve social flexibility. In total, for each of the three facets of Neutra's theory that are tested in this paper, there is mathematical evidence that the majority of these are strongly present in his completed buildings.

\section{Acknowledgments}

An ARC Fellowship (FT0991309) and an ARC Discovery Grant (DP1094154) supported the research undertaken in this paper. 


\section{References}

BATTY, Michael. (2001). "Exploring isovist fields: space and shape in architectural and urban morphology." Environment and Planning B: Planning and Design, 28, 123-150

BATTY, Michael. and Carvalho, Rui. (2003). A rigorous definition of axial lines: ridges on Isovist fields. London, University College London.

BATTY, Michael. and Rana, Sanjay. (2004). "The automatic definition and generation of axial lines and axial maps." Environment and Planning B: Planning and Design 31: 615-640.

BENEDIKT, Michael. (1979) "To take hold of space: Isovists and Isovist view fields." Environment and Planning B: Planning and Design 1: 47-65.

BENEDIKT, Michael., Burnham, C.A., (1985). "Perceiving Architectural Space: From Optic Arrays to Isovists", W.H. Warren, R. E. Shaw (Eds.), Proceedings; Persistence and Change: First International Conference on Event Perception, Hillsdale, NJ, Lawrence Erlbaum Associates, pp. 103-114.

BOESIGER, Willy. ed. (1966). Richard Neutra 1961-66: Buildings and Projects. London, Thames and Hudson.

DESYLLAS, J. (2000). The relationship between urban street configuration and office rent patterns in Berlin. London, University College London.

HANSON, Julienne. (1998). Decoding Homes and Houses. Cambridge, Cambridge University press. HAQ, Saif. (2003). "Investigating the syntax line: configurational properties and cognitive correlates." Environment and Planning B: Planning and Design 30: 841-863.

HAQ, Saif. and Girotto, Sara. (2003). Ability and Intelligibility: Wayfinding and Environmental Cognition in the Designed Environment. Space Syntax: 4th International Symposium. London. 68.61-68.20.

HILLIER, Bill. (1996). Space is the Machine. London, Cambridge University Press.

HILLIER, Bill. and Hanson, Julienne (1984). The Social Logic of Space. Cambridge, Cambridge University Press.

HILLIER, Bill. R. Brudett, et al. (1987). "Creating Life: or does architecture determine anything?" Architecture and Behaviour 3: 233-250.

HILLIER, Bill., Penn, Alan., Hanson, Julienne., Grajewski, T, and Xu, J. (1993). "Natural movementOr, Configuration and attraction in urban pedestrian movement." Environment and Planning B: Planning and Design 20(1): 29-66.

HINES, Thomas. S. 1982. Richard Neutra and the search for modern architecture: a biography and history. Berkeley, University of California Press.

KOCH, Daniel (2010) “Architecture Re-Configured”, The Journal of Space Syntax. 1, 1: 1-16

LAMPRECHT, Barbara. (2000). Neutra: Complete works. London, Taschen.

LAVIN, Sylvia. (2004). Form Follows Libido: Architecture and Richard Neutra in a Psychoanalytic Culture. London, The MIT Press.

MARLIN, William. (1989). Near Nature: Late Essays of Richard Neutra. Santa Barbara, Capra Press.

MONTELLO, Daniel. R., 2007, 'The contribution of space syntax to a comprehensive theory of environmental psychology', Proceedings, 6th International Space Syntax Symposium, Istanbul. iv01-iv12.

NEUTRA, Richard. (1954). Survival Through Design. New York, Oxford University Press.

NEUTRA, Richard. (1956). Life and Human Habitat. Stuttgart, Mensch und Wohnen.

NEUTRA, Richard. (1971). Richard Neutra Building With Nature. Stuttgart, Universe Books.

OSTWALD, Michael J. (2011). "The Mathematics of Spatial Configuration: Revisiting, Revising and Critiquing Justified Plan Graph Theory." Nexus Network Journal 13(2): 445-470.

PEPONIS, John., Ross, Catherine., and Rashid, Mahbub. (1997). "The structure of urban space, movement and co-presence: The case of Atlanta." Geoforum 28(3-4): 341-358. 
PEPONIS, John., Wineman, Jean. Rashid, Mahbub., Kim, S. and Bafna, Sonit. (1997). On the Generation of Linear Representations of Spatial Configuration. Space Syntax: First International Symposium. London.

PEPONIS, John., Zimring, Craig., and Choi, Yoon Kyung. (1990). "Finding the building in way finding." Environment and Behavior 22(5): 555-590.

RASHID, Mahbub., Wineman, Jean. and Zimring, Craig. (2009). "Space behaviour, and environmental perception in open plan offices: a prospective study." Environment and Planning B: Planning and Design 36: 432-449.

RATTI, Carlo. (2004). "Urban texture and space Syntax: some inconsistencies." Environment and Planning B: Planning and Design 31(487-499).

READ, S. (1999). "Space syntax and the Dutch city." Environment and Planning B: Planning and Design 26: 251-264.

SACK, Manfred. 1992. Richard Neutra. Zürich: Verlag für Architektur.

SHPUZA, Ermal., and Peponis, John. (2008). "The effect of floorplate shape on office layout integration." Environment and Planning B: Planning and Design 35: 318-336.

TURNER, A. (2004). Depthmap 4. A researcher's Handbook. London, Bartlett School of graduate studies, University College London.

TURNER, Alasdair., Penn, Alan., and Hillier, Bill. (2005). "An algorithmic definition of the axial map.” Environment and Planning B: Planning and Design 32: 425-444.

\section{About the Authors}

\section{Michael Dawes}

Michael Dawes is a graduate architect who is currently a research assistant undertaking space syntax analysis on twentieth century houses.

\section{Prof. Michael J. Ostwald}

Professor Michael J. Ostwald is Dean of Architecture at the University of Newcastle, Australia and a Visiting Professor at RMIT University (Melbourne). He has a PhD in architectural history and theory and a higher doctorate (DSc) in the mathematics of design. He has lectured in Asia, Europe and North America and has written and published extensively on the relationship between architecture, philosophy and geometry. Michael Ostwald is a member of the editorial boards of the Nexus Network Journal and Architectural Theory Review and he is co-editor of the journal Architectural Design Research. 